Peer Reviewed Review openaccess

\title{
Emerging applications in mass spectrometry imaging; enablers and roadblocks
}

\author{
Cristina Russo, ${ }^{\mathrm{a}}$ Cameron Heaton, ${ }^{\mathrm{b}}$ Lucy Flint, ${ }^{\mathrm{b}}$ Oana Voloaca, ${ }^{\mathrm{b}}$ Sarah Haywood-Small, ${ }^{\mathrm{b}}$ Malcolm Ronald Clench, ${ }^{\mathrm{b}}$ \\ Simona Francese ${ }^{\mathrm{b}}$ and Laura Margaret Cole $\mathrm{e}^{\mathrm{b}, *}$ \\ aMiddlesex University, The Burroughs, Hendon, London NW4 4BT, UK \\ bSheffield Hallam University, Howard St, Sheffield, S1 1WB, UK
}

Contacts

Cristina Russo: https://orcid.org/0000-0002-9776-8897

Cameron Heaton: https://orcid.org/0000-0002-4479-3861

Lucy Flint: https://orcid.org/0000-0001-6187-3081

Oana Voloaca: https://orcid.org/0000-0003-0131-6907

Sarah Haywood-Small: https://orcid.org/0000-0002-8374-9783

\author{
Malcolm R. Clench: https://orcid.org/0000-0002-0798-831X \\ Simona Francese: https://orcid.org/0000-0002-1381-1262 \\ Laura M. Cole: L.Cole@shu.ac.uk, \\ https://orcid.org/0000-0002-2538-6291
}

Mass spectrometry imaging (MSI) is a powerful and versatile technique able to investigate the spatial distribution of multiple non-labelled endogenous and exogenous analytes simultaneously, within a wide range of samples. Over the last two decades, MSI has found widespread application for an extensive range of disciplines including pre-clinical drug discovery, clinical applications and human identification for forensic purposes. Technical advances in both instrumentation and software capabilities have led to a continual increase in the interest in MSI; however, there are still some limitations. In this review, we discuss the emerging applications in MSI that significantly impact three key areas of mass spectrometry (MS) research-clinical, pre-clinical and forensics-and roadblocks to the expansion of use of MSI in these areas.

Keywords: mass spectrometry imaging (MALDI), secondary ionisation mass spectrometry (SIMS), desorption electrospray ionisation (DESI), laser ablation inductively coupled plasma (LA-ICP), liquid extraction surface analysis (LESA), imaging mass cytometry (IMC), biomolecular imaging, technical advancements, imaging software

\section{Introduction}

Observing the spatial distribution of an endogenous or exogenous molecule has great potential for many applications. Mass spectrometry imaging (MSI) has evolved from existing MS techniques enabling identification and quantification of an analyte, whilst retaining spatial information. In MSI, spectra are acquired in regular rows or raster lines to cover a region of interest (ROI) on a sample.
The mass spectrum plotting mass to charge ratio $(\mathrm{m} / \mathrm{z})$ values versus ion intensities is generated for each raster point or pixel. These can then be reconstituted, using software, into a molecular "image" where the distribution of individual or multiple $\mathrm{m} / \mathrm{z}$ values can be selected and visualised within the sample. MSI, therefore, enables the simultaneous study of the distribution of multiple

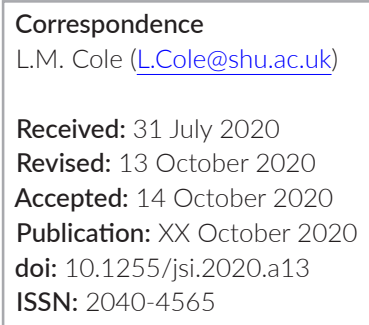

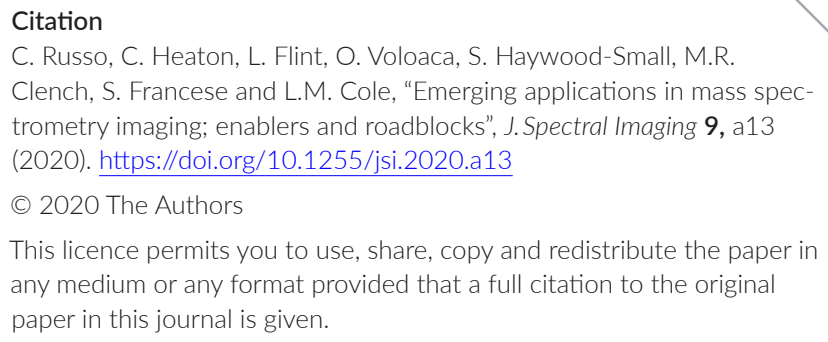


molecular species in a sample in an untargeted, label-free manner.

Since its development for biomolecular imaging by the Caprioli group in 1997, ${ }^{1}$ MSI has established itself to encapsulate many bioanalytical applications, analysing a variety of samples including single-cells, three-dimensional cultures, animal tissues, whole rodents, patient microarrays and biopsies, fingermarks, and human hair. ${ }^{2-8}$ Over the last decade, technical advancements in instrumentation have allowed vast improvements in MSI speed, spatial resolution and sensitivity. In addition, MSI modalities employing a wide range of ionisation sources have been developed including:

matrix-assisted laser desorption ionisation (MALDI), a soft ionisation technique which employs laser energy and an absorbing matrix;

- secondary ionisation mass spectrometry (SIMS), using a focused primary beam of ions resulting in the analysis of secondary ions ejected from the sample surface;

- desorption electrospray ionisation (DESI), an ambient ionisation methodology via a solvent spray;

- laser ablation inductively coupled plasma (LA-ICP) involves a nanosecond-pulsed laser to the sample surface; and
- liquid extraction surface analysis (LESA) via direct micro-junction solvent extraction.

Early images took 1-2 min per pixel at $25 \mu \mathrm{m}$ spatial resolution, ${ }^{1}$ compared to modern-day instrumentation where the image acquisition time has decreased by a factor of up to 20 times. ${ }^{9}$ This is an astounding advancement in two decades and has allowed ever more diverse applications to be undertaken; for example, MALDI-MSI of a whole rodent body section at $100 \mu \mathrm{m}$ pixel size has been reported as being acquired in less than $13 \mathrm{~h}$ (Figure 1).

MSI has had a dramatic influence on the pharmaceutical industry, particularly in pre-clinical drug discovery. The development of high-resolution imaging has enabled precise localisation of therapeutics simultaneously with tissue biomarkers for effective compound efficacy and safety profiling. MSI can be used to identify failures in drug development thus preventing high attrition rates, significantly reducing financial costs and project timings.

Improvements in spatial resolution, acquisition time and reproducibility have meant that the use of MSI in clinical settings seems closer than ever. The idea of carrying out MS-based analysis either in situ or during real-time surgery on patient biopsies will contribute to making a

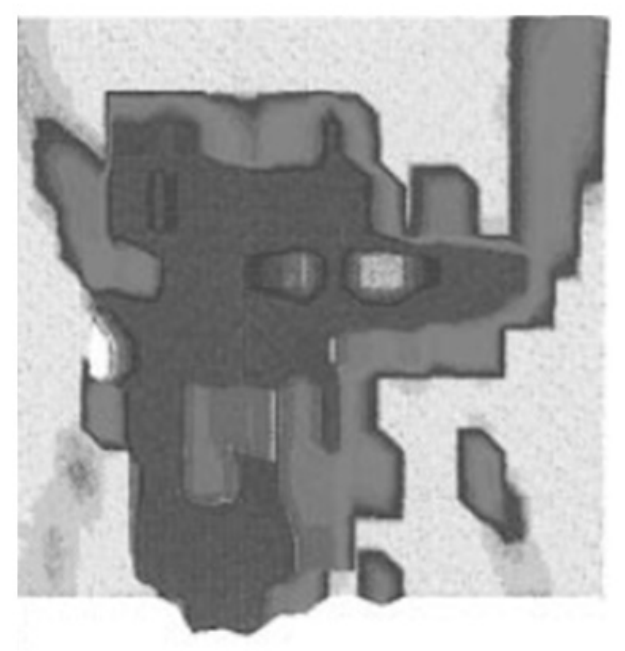

b

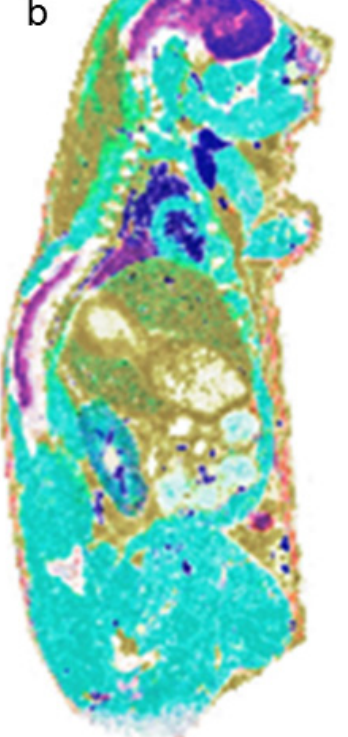

Figure 1. A comparison of imaging capabilities in terms of spatial resolution, area of acquisition and speed over the last two decades. a) Shows a MALDI image of an aggregate of human buccal mucosa cells at $25 \mu \mathrm{m}$ laser spot size in 1997. b) In contrast, a MALDI image of an entire rodent body section at $100 \mu \mathrm{m}$ in 2017 (not to scale, adapted from Reference 1 and Chemical \& Engineering Magazine, front cover, 5 June 2017 [credit ImaBiotech]). 
precision medicine a reality. ${ }^{10}$ Precision medicine is the ideal process in diagnosis, care and treatment of one's condition, a step away from the classic "signs-and-symptoms" approach. Monitoring the alterations of specific endogenous molecules (such as lipids, peptides and metabolites) in a spatially-resolved manner can provide valuable insights into the normal or diseased state and can be used as a personalised tool for diagnosis, prognosis and monitoring of disease. Already, MSI in clinical research has led to the discovery of disease biomarkers, especially in oncology, and helped understanding the molecular mechanisms causing certain pathologies. ${ }^{11,12}$ An insightful study by the Prideaux research group in 2018 reported on mycobacterial biomarkers and the co-registration of drugs to treat tuberculosis in animal models using MALDI-MSI. ${ }^{13}$ Images included the spatial distribution of bacterial populations in distinct regions of ex vivo tissues with the ability to visualise patterns of drug delivery.

MSI remains a largely academic exercise in the field of forensic analysis apart from its use in the analysis of fingermarks. Both SIMS and MALDI feature in the Home Office Fingermark Visualisation Manual (FVM) ${ }^{14}$ as Category $\mathrm{C}$ techniques indicating processes "at a developmental stage exhibiting potential [...] an optional process for occasional operational use [...] when Category A processes have been exhausted". Category A processes are well established and include optical (i.e. multispectral imaging, infrared reflection, ultraviolet reflection etc.), chemical (i.e. superglue fuming, ninhydrin, acid dyes etc.) and physical processes (i.e. vacuum metal deposition, enhancing powders etc.).

Unlike SIMS, due to the vast body of knowledge, wider compatibility with Category A processes and implementation in some casework, MALDI-MSI is now in the process to be promoted, in the next FVM edition, to Category $B$ indicating an "established process [...] likely to offer benefits [...] for occasional operational use [...] and when all Categories A options have been exhausted". Additionally, amongst all the MSI techniques, to the best of the authors' knowledge, MALDI has been the only one that has been used in operational casework both in the UK ${ }^{15}$ and overseas. These circumstances are testimony to the continuous advancements of MALDI-MSI in this field. However, full implementation (including in a court of law) is still somewhat hindered by the challenge of undertaking method validation which would require testing robustness and effectiveness of the methods against a large number of fingermarks from a large number of donors, surfaces of depositions, environmental conditions and against an as large number of forensic enhancement techniques as possible. This is not considered original work by funders and it is often the given reason why such studies are not funded, despite being the last hurdle prior to full operational implementation. This potentially negates the considerable impact on the criminal justice system and on safe societies that operational implementation of MALDI-MSI could offer.

The aim of this perspective is to look at the issues in MSI, both technical and non-technical, that are currently "roadblocks" to its further adoption in real-world applications. The roadblocks to be discussed are: obtaining appropriate samples, complex sample preparation, long sample analysis times, poor molecular specificity, poor sensitivity and poorly developed data processing tools. The literature has been examined and proposed solutions that have emerged in recent years for these particular roadblocks are discussed.

\section{Roadblocks and enablers Obtaining samples}

Clinical samples

Many clinical institutions support research by providing tissue samples harvested from patients. Public opinion has tremendously changed with more and more people being willing to donate biological material in order to support further research. However, such samples are a finite resource and, therefore, experimentation with them must be justified ethically. In addition, many MS laboratories have little experience in the safe and ethical handling (and storage) of healthy and diseased human tissue.

There are three main strategies in place for obtaining clinical samples for MSI studies: use of a tissue bank (banking model), a prospective collection model and a combination of the two. ${ }^{16}$ The prospective collection model allows a pre-selective element where the desirable tissue type is stated, type of storage and corresponding number of samples required before collection. Whereas acquiring samples via a banking model limits the choice and relies on what is already archived. In addition to these methods there is also "catch as catch can", which describes another, yet unreliable tissue collection strategy which potentially risks legal and ethical violation. This is so, due to there being no quality controls or 
quality assurance in place to ensure that suitable storage and tissue processing meets national standard operating procedures. Samples are taken as and when tissue is available on an ad hoc basis, reliant on when collection timescales allow. "Catch as can" methods can, therefore, result in tissue of substandard grade and not being a true representation of the tissue from its origin.

\section{Pre-clinical samples}

Animal tissues are conventionally used for pre-clinical studies in drug disposition, efficacy, safety and model characterisation, this due to the in vivo conditions closely resembling human metabolic processes. Such tissues are readily available with pharma, contract research organisations and universities having licensed facilities for the ethical use of animals in scientific research. Animal tissues have been widely used in MSI for the study of disease and drug absorption/efficacy/toxicity. ${ }^{1,4,5}$ Whilst the use of animal models in pre-clinical studies is currently the accepted paradigm, there are issues on the horizon. Attitudes in society to the use of animals in research are changing, and criticisms that animals are an inappropriate model to represent the human body are becoming more widespread. ${ }^{17}$ Tissue engineered models are emerging as a valuable complementary/alternative in vitro tool to the use of animals in pre-clinical drug discovery and have the potential to make significant positive impact on the 3Rsreduction, replacement and refinement-agenda for the use of animals in scientific research. ${ }^{18}$ The combination of 3D tissue culture systems with MSI, offering, as it does, the ability to study drug and drug responses simultaneously in a rapid label-free manner, is a research field that has huge promise for the future.

The Hummon group reported the use of tumour spheroids with MSI and they were able to demonstrate the ability of the technique to identify specific hypoxic regions within colon cancer spheroids. ${ }^{3} \mathrm{MSI}$ in combination with spheroids has been used for the detection of chemotherapeutics, their metabolites and biological responses within. ${ }^{19-21}$ Liu et al. ${ }^{21}$ described drug distributional patterns of irinotecan within the necrotic core of spheroids $24 \mathrm{~h}$ after treatment, stating high metabolism within the outer regions due to the presence of irinotecan metabolites.

Organoid models, particularly 3D models of full thickness skin, have been extensively used in MSI. ${ }^{22,23}$ This combination has been used to evaluate drug penetration and drug effects, wound healing and infection. ${ }^{24,25}$ In a recent report ${ }^{22}$ a validated quantitative methodology employing a 3D skin model was used to study the effect of an enhancer for drug absorption within the epidermis of a living skin equivalent model ${ }^{24}$ (Figure 2). Successful demonstration of these capabilities has proved high value for pre-clinical drug development specifically for compound efficacy and safety analysis. Yet, this area of research is still emerging, so the extent of applications in MSI with 3D cultures holds great potential. This is specifically due to recent developments in tissue engineering that have produced microfluidic devices and 3D bioprinting technology with more representative microenvironment conditions of in vivo.

\section{Samples for forensic analyses}

Fingermark imaging is one of the widest reported applications of MSI in forensics. The recovery of intelligence around a suspect or the crime being investigated from the molecular content of a fingermark (profiling), whilst visualising the interested molecule on the fingermark ridge pattern (imaging) (Figure 3), offers unprecedented information to the investigators. ${ }^{26,27}$

This information can be used to triage the fingermarks within the crime scene management strategy and/or to narrow down the pool of suspects. However, one of the most used forensic protocols for collecting fingermarks at the crime scene includes enhancement of the marks using powders applied from the same pot with the same brush. This inevitably introduces cross-contamination of evidence which, though not affecting the biometric information, affects the forensic meaning of a given substance detected in a fingermark. In addition, several Police Forces in the UK are moving away from physical fingermark recovery (for example through tape lifting) and towards electronic photo capture and real-time remote transmission. Should this process be extended to major crimes as well, where MALDI-MSI finds application, the opportunity to offer intelligence, complementary to that yielded by classic police investigation, will be lost. If the availability and the "molecular meaningfulness" of fingermarks are to be maintained, both of these roadblocks must be considered at the point of sample recovery. One way around sample cross-contamination was reported by Reed et al. ${ }^{28}$ with the development of a gun depositing the powder in a contactless manner. The device was described in the UK patent application GB 2504276 , which was let to lapse as it is under further industrial development. Of course, the only way to avoid exclusive 

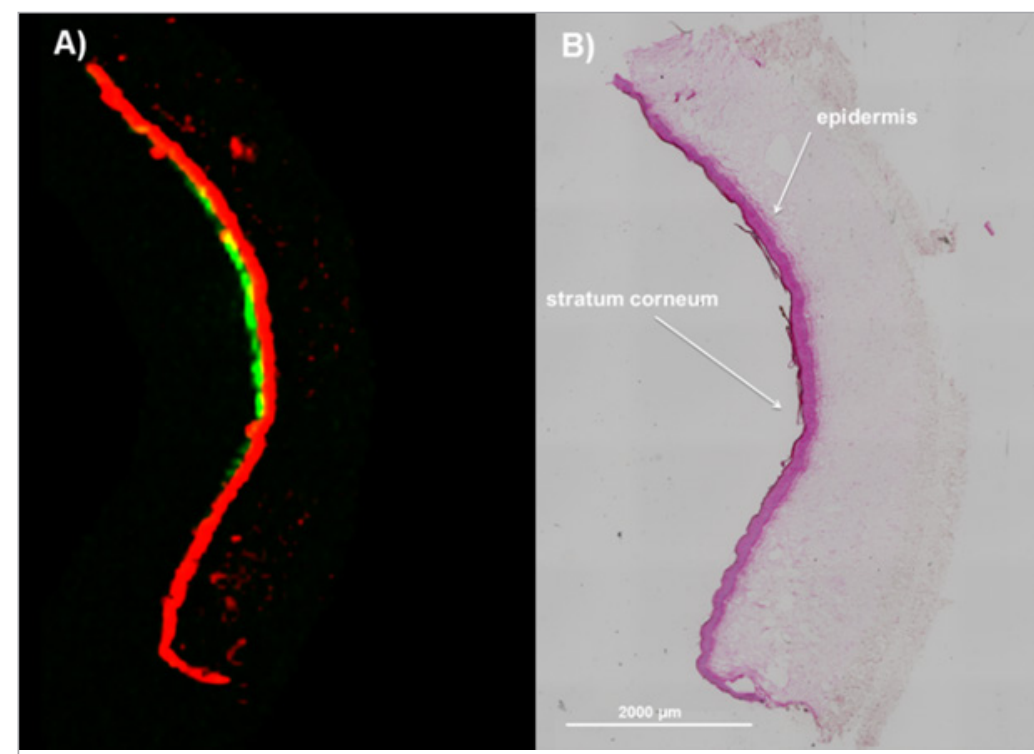

Figure 2. A) MALDI-MSI of a living skin equivalent model, Labskin, showing marker ions of the stratum corneum (in green, $[\mathrm{M}+\mathrm{H}]^{+} ; \mathrm{m} / \mathrm{z}$ 264) and the epidermis (in red, $[\mathrm{M}+\mathrm{H}]^{+} ; m / z$ 184). B) Histological staining of the same section after MSI analysis (adapted from Proteomics, front cover, 18 July 2018 [credit C. Russo]).

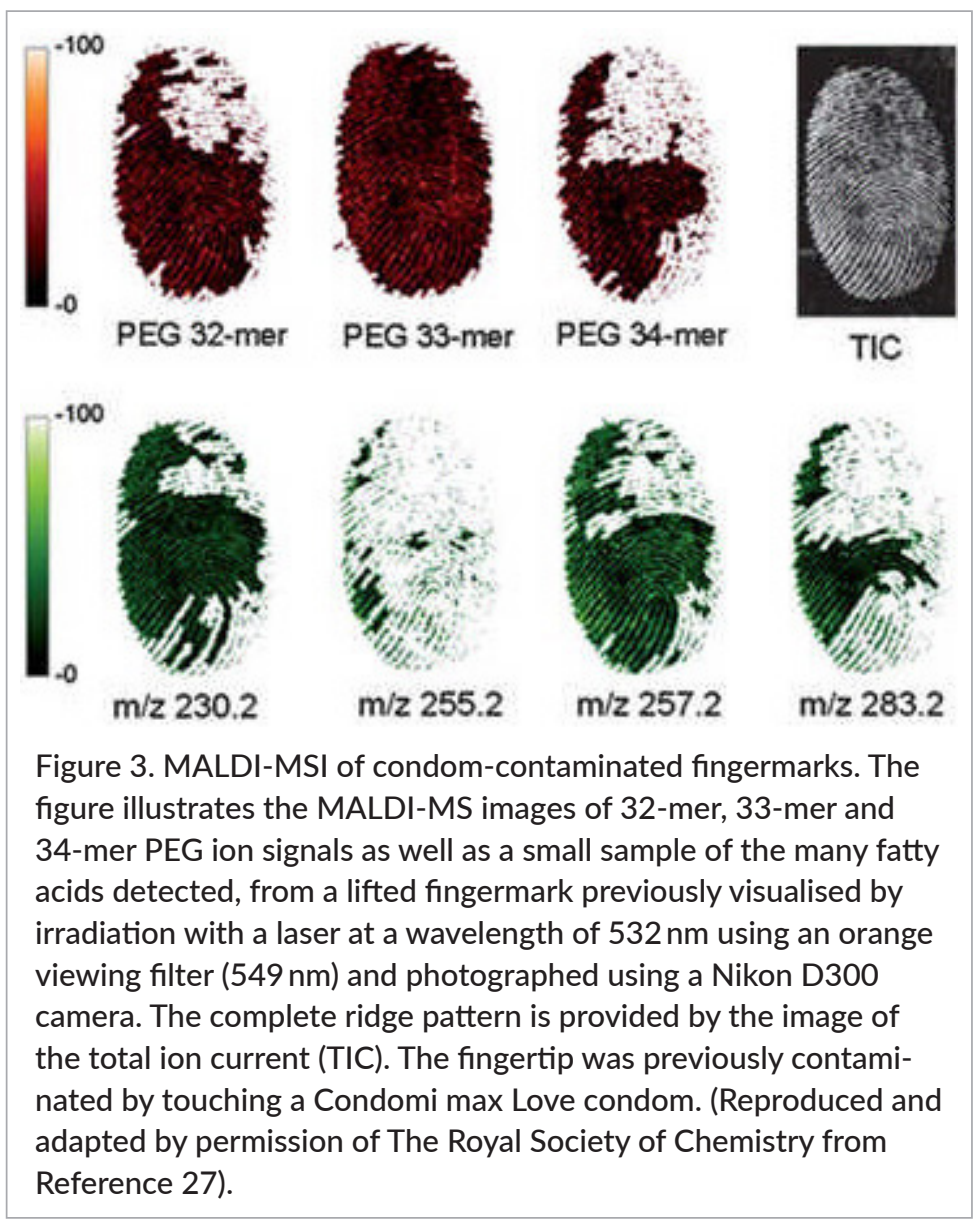


mobile transmission of the evidence and to influence practice would be to provide continuous examples in actual police casework that the intelligence provided by the application of MSI is additional and complementary to police investigation, as demonstrated by Bradshaw et al. ${ }^{27}$ Presently, in major crimes (murder, rapes etc.) fingermarks are still being lifted.

\section{Sample preparation Pre-preparation}

\section{Embedding and sectioning}

Maintaining tissue integrity is imperative in MSI experiments in order to preserve analyte localisation. Commonly, analysis is conducted on cryo-sectioned tissue sections, often collected and prepared with MSI as a primary analytical endpoint. Smaller, more fragile tissues often require supportive materials, embedding samples for handling purposes. Embedding several tissues from the same study has also proven beneficial for reducing sample preparation time and preventing molecular changes via "freezer burn" to tissue sections in the cryostat. ${ }^{29}$ MSI compatible materials that do not interfere with analysis include gelatin ${ }^{30}$ and carboxymethylcellulose (CMC). ${ }^{31}$ Alternatively, poly[N-(2-hydroxypropyl)methacrylamide] (pHPMA) was specifically developed for MSI, as it is liquid at $-8{ }^{\circ} \mathrm{C} .{ }^{32}$ This low temperature minimises possible thawing of tissues unlike gelatin which requires higher temperatures $\left(\sim 25-50^{\circ} \mathrm{C}\right)$ during embedding. A more recent study optimised a sample embedding protocol with an ice-cold hydrogel composed of hydroxypropyl methylcellulose (HPMC) and polyvinylpyrrolidone (PVP). ${ }^{33}$ Dannhorn et al..$^{33}$ assessed the compatibility of the hydrogel demonstrating no interfering effects with MALDI, DESI and SIMS imaging methods or delocalisation of analytes.

In a clinical setting, the standard preservation process for tissues collected for pathology is to formalin fix and then paraffin embed the tissue to create so called Formalin Fixed Paraffin Embedded (FFPE) tissues. Such samples are suitable for indefinite storage. Despite the advantages of the use of fresh frozen tissue, in terms of the range of molecules that can be detected within, for widespread adoption of MSI in the clinic to occur, ways of preparing FFPE tissues are required. Various ways to achieve this have been developed including adding a de-paraffinisation step prior to matrix application, ${ }^{34}$ addition of enzymes or changing digestion strategies. ${ }^{35}$ Moreover, section thickness has been reported to influence peak intensity, with $1 \mu \mathrm{m}$ sections presenting up to three-fold higher intensities compared to conventional $5 \mu \mathrm{m}$ sections. ${ }^{36,37}$

\section{Storage}

Appropriate storage for tissues is crucial to retain sample integrity and ensure accurate results. When considering conventional immunohistochemistry, whole tissue samples can be stored at $-80^{\circ} \mathrm{C}$ up to a year without degradation that would impact on the study of protein distribution. Storage of tissues and sectioned samples for MSI presents more challenges as tissue sections are vulnerable to excessive ice formation and condensation, resulting in molecular degradation and delocalisation. Efforts to reduce this impact have included steps to remove excess moisture by drying the sample either by desiccation or freeze-dry techniques. ${ }^{38,39}$ This, however, can add to sample preparation time $(\sim 2 \mathrm{~h})$ and is not completely effective. Alternatively, a recent study conducted by Swales et al. ${ }^{40}$ established a protocol of desiccating the sample with nitrogen after thaw mounting, and then vacuum packing the slides prior to storage. Maintaining the sample in a vacuum environment ensures that the molecular distribution within a tissue is stored in its "life-like" state. By employing this technique, the study observed significant stabilisation of molecules and minimised delocalisation, thus improving imaging results.

\section{Sample preparation issues associated with specific imaging modalities}

\section{MALDI}

Matrix application is critical to success in preparing samples for MALDI imaging. Selecting an appropriate matrix is critical, as is the application. There are four well-established methods of applying matrix to samples before MSI; automatic and manual spray systems, sublimation and acoustic vibrational spotters. Spray coating is the most popular method of application, with a variety of commercial spray systems on the market (i.e. SunChrom SunCollect and HTX TM-Sprayer). ${ }^{41,42}$ The number of layers, flow rate and speed of deposition can all be accurately controlled. The main advantage of automatic sprayers are that ROIs can accurately be selected, leaving unwanted areas free of matrix and making efficient use of matrix. However, they are slower than other methods. 
Manual sprayers cover the whole sample and the quantity of matrix applied is less precise, but are a much simpler and cheaper alternative. Sublimation results in a homogenous matrix coating with a very small crystal sizes, and, importantly, without the use of solvents that can cause analyte delocalisation in certain samples. Acoustic spotters (such as Labcyte Portrait 630 and Bruker ImagePrep) can apply very small droplet sizes and have their parameters easily changed, but are slow and expensive. ${ }^{43,44}$

Generally, the presence of solvents, when matrix sprayers are employed, results in the formation of relatively large crystals in diameter (30-60 $\mu \mathrm{m})$, larger than the smallest laser spot size for most MALDI instruments $(5-15 \mu \mathrm{m})$. Advances in the complexity of commercial sprayers allow the user to control the sample stage temperature, enabling further refinement of the speed of crystal formation, consequently allowing a reduction in crystal size. Acoustic vibration spotters produce droplet sizes in the region of 20-50 $\mu \mathrm{m}$, whereas sublimation can generate $<1 \mu \mathrm{m}$ crystals. Allowing fine-tuning of matrix application parameters can lead to homogenous deposition and smaller, more consistent crystal formation, which can translate into higher resolution molecular imaging.

\section{Ambient techniques}

Ambient techniques benefit from virtually no (or very little) sample preparation steps, and this has been a major contribution to their recently gained popularity. It enables swift analysis upon receipt of the sample, drastically improving throughput times. One example of the usefulness of this comes from work on drug-induced lipidosis in rodent tissues reported by Dexter et al. ${ }^{4}$ They used DESI imaging to study the distribution of amiodarone, a wellknown lipidosis-inducing drug. It was shown that not only does DESI provide operational simplicity at atmospheric pressure and requires no sample preparation, but it also allows for repeat analysis of the same section several times. This drastically reduces delocalisation, allows for application of simple registration routines for data acquisition, and allows for detection of molecules in both positive- and negative-ion mode without the need for serial sectioning. However, a limitation of this technique still lies in the relatively poor spatial resolution $(30-150 \mu \mathrm{m})$ when compared to other established imaging platforms. ${ }^{4}$

The ultimate goal of carrying out MSI in vivo with no sample preparation needed is becoming more and more feasible. Whilst there appear to be no reports of real-time
MSI in surgical settings to date, tools such as the iKnife and MasSpec Pen have been shown to identify borderline tumours in real-time by analysing specific biomarkers with no sample preparation required. ${ }^{45,46}$ These techniques do have the potential to be coupled with MSI and provide qualitative and spatial information about the tumour microenvironment to aid a surgeon to distinguish the cancerous tissues in "real-time" in a manner that has never been envisioned before.

\section{Sample preparation issues associated with specific analyte/sample types of current interest}

Hair

Although fingerprints make up most publications in forensic MSI, other forensically relevant evidence have had this technique applied. Strands of hair (in the order of 20-100 mg for example) are normally the specimen of choice for determining chronic drug use. ${ }^{47}$ To give an estimated window of time exposure, the hair shaft can be cut into $1 \mathrm{~cm}$ lengths and analysed typically by liquid chromatography-MS or gas chromatography-MS. ${ }^{48,49}$ However, following the growing interest in forensic MSI, hair has been molecularly imaged to give a visual indication of drug abuse. This method reduces sample preparation time, allows the detection of a narrower time frame and also reduces the amount of sample required. Beasley et al. ${ }^{50}$ detected notoriously poorly ionising cannabinoids in single hair stands for the first time using a combination of cannabinoid derivatisation and MALDI-MSI. External contamination is a present challenge for hair analysis and external solvent washes are required in order to remove such contaminants.

To facilitate another dimension of hair analysis, Flinders et al. ${ }^{51}$ developed a novel device which allowed precision, longitudinal sectioning of hair strands enabling clear lateral visualisation of the cuticle, medullar and cortex. This group, from the Netherlands, then also successfully demonstrated an approach using multiple-reaction monitoring (MRM) to detect metabolites in hair sections differentiating between cocaine users and externally contaminated hair. ${ }^{8}$ This is a benefit unique to MSI, which can simultaneously perform MRM and provide the visual distribution of the exact location of these analytes (Figure 4). Analysis of the hair samples took around $3 \mathrm{~h}$ compared to the current methodology which takes $1 \mathrm{~h}$; however, sample preparation for the current methodology takes around 1 day, whilst MALDI-MS sample preparation is 
$1 \mathrm{~h}$, thus indicating a significantly higher overall speed of hair processing using MALDI-MSI.

\section{Biopharmaceuticals}

Biopharmaceuticals have received considerable attention over recent years, becoming one of the fastest growing sectors within the pharmaceutical industry. The rapid growth of biopharmaceuticals has thus challenged MSI to progress their detection and imaging with the same momentum. Detecting large molecular mass molecules of $40-150 \mathrm{kDa}$ by MSI presents issues associated with their low ionisation efficiencies leading to poor sensitivity, which have hindered the detection of biologics within tissues.
The employment of proteomic strategies for the detection of biologics in vivo has had some success. An in-source decay (ISD) top-down fragmentation approach exploited by Ait-Belkacem et al. ${ }^{52}$ detected the monoclonal therapeutics, bevacizumab and palivizumab within the brain. With the ability to rapidly fragment proteins, the ISD approach has no limitation on mass range proving beneficial for larger molecular weight imaging. Yet this strategy has its drawbacks. With the lack of precursor ion selection, due to in-source fragmentation, identifying biologic-specific peaks in complicated spectra amongst multiple proteins proves challenging, especially since this technique produces relatively low ion yield of fragments. However, the ISD approach does allow for second

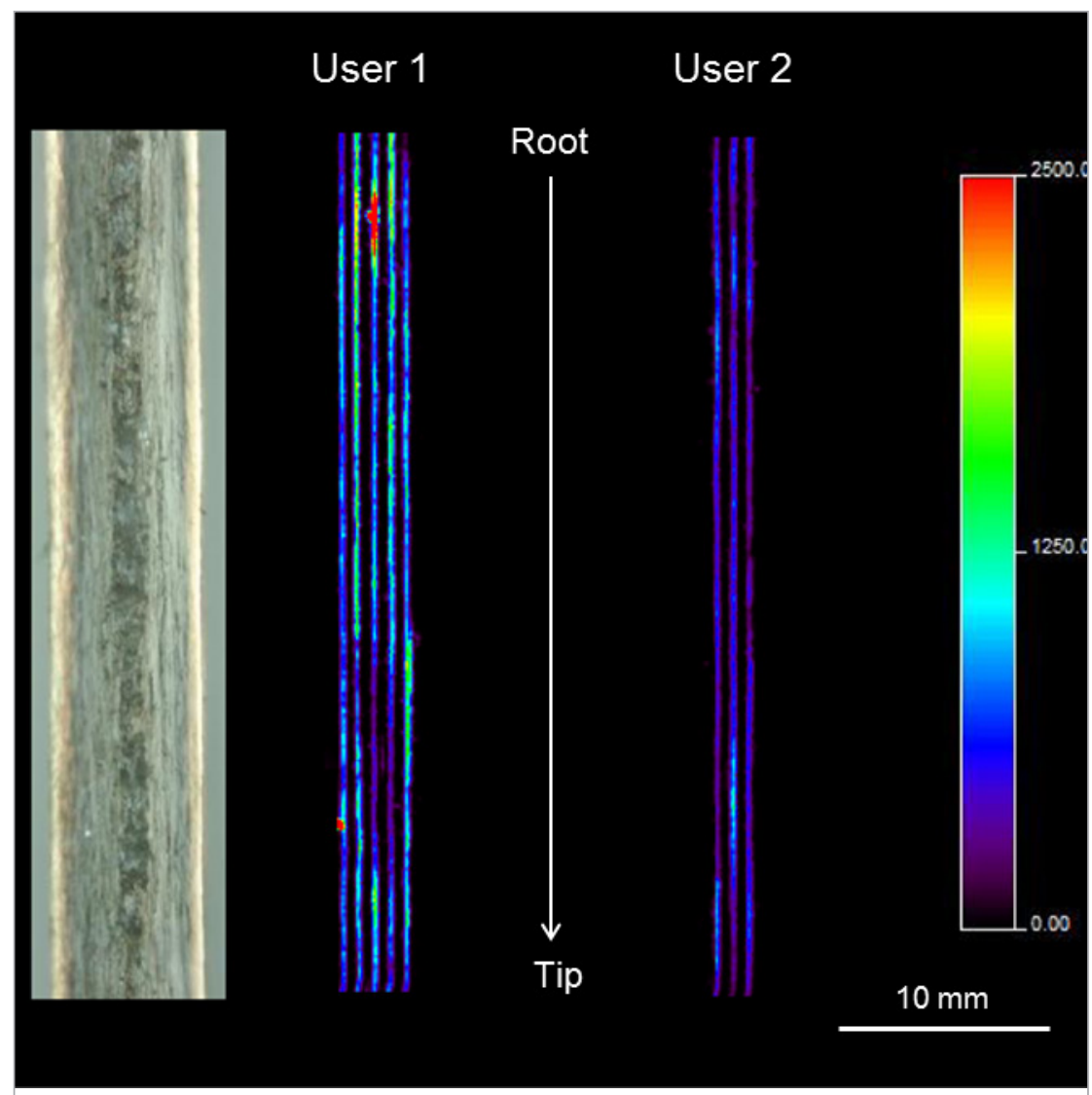

Figure 4. MALDI-MS/MS image of longitudinally sectioned drug users' hair samples (insert shows optical image of longitudinally sectioned hair). The MALDI-MS/MS image shows the differential distribution (quantities and location) of the product ion at $\mathrm{m} / \mathrm{z} 182$, derived from the precursor ion of cocaine at $\mathrm{m} / \mathrm{z} 304$ within the hair shaft of two cocaine users. The length of the analysed hair samples was $4 \mathrm{~cm}$ corresponding to a hair growth period of 4 month. Since the spatial resolution along the hair is $150 \mu \mathrm{m}$, each pixel is equivalent to approximately $12 \mathrm{~h}$ of growth (adapted and reproduced from Reference 8 under the Creative Commons Licence http://creativecommons. org/licenses/by/4.0/). 
fragmentation known as $T^{3}$-sequencing, which will enable amino acid sequencing for confident identification. ${ }^{53}$

Alternatively, a novel approach of an on-tissue reduction and alkylation was demonstrated by Liu et al..$^{54}$ for the detection of a monoclonal drug, cetuximab in tumour spheroids and organoids. The method separates the antibody into heavy and light chains for the detection at a smaller mass range, i.e. from $150 \mathrm{kDa}$ to $20-50 \mathrm{kDa}$. Limitations of this practice can result in low fragmentation efficiencies, which can impact the ability to accurately isolate the ion of interest from considerable signal of endogenous species. Initial profiling of the reduced antibody is, therefore, necessary to correctly identify the biologic. A significant lack of publications demonstrates the need for further method development for biologic imaging. Yet with the progress of the two reports stated there is potential for MSI in pre-clinical drug development to be utilised in the biopharmaceutical industry.

\section{Sample analysis} Time of acquisition

One of the main roadblocks discussed which prevents MSI progressing into routine use in industry is the time taken for image acquisition. The overall time required for an MSI experiment to be undertaken encompasses sample preparation, acquisition time and data processing. Hence, much of the progress in technological development has focused on shortening the time it takes to cover these stages.

In MALDI imaging, the spot-to-spot acquisition time and the laser repetition rate have historically been limiting factors in the overall speed of acquisition. The widespread adoption of raster imaging (line scanning) for MALDI-MSI and in addition to the increase in the typical repetition rate of lasers used to $1-2 \mathrm{kHz}$, represent real game changers in the speed of acquisition for this modality. Typically, an area of the size of a fingermark may have taken more than $20 \mathrm{~h}$ to be imaged with a relatively good spatial resolution ( $100 \mu \mathrm{m}$ pixel size) even on an instrument fitted with a $1 \mathrm{kHz}$ laser, if acquiring in spot-to-spot mode. In line scanning mode this can be achieved in 30 min. Recent advances have pushed the speed boundaries even further by the integration of the MMALDI source on instruments such as Waters QTOF Synapt (Waters, Wilmslow, UK) and the Bruker Rapiflex (Bruker, Bremen Germany). ${ }^{55}$ Now an image, the size of a fingermark (at $100 \mu \mathrm{m}$ pixel size), can be acquired in as little as $10 \mathrm{~min}$. Such a significant increase in the speed of acquisition has benefits for all fields using MSI.

\section{Spatial resolution}

Another area that has seen constant improvement in MSI is the spatial resolution achievable. In less than 10 years, the available spatial resolution has improved on commercially available instrumentation from $100 \mu \mathrm{m}$ down to sub-micron. The Spengler group published a study pertinent to this field, looking at the correlation between the formation of ions and laser spot size in highresolution MALDI imaging. ${ }^{56}$ In addition, they reported on laser optical resolution and the dependence of ion signal intensities on both laser fluence and laser beam profile within the spatial resolution range 1.1-8.4 $\mu \mathrm{m}$. The authors indicated that their data supported the view that there were no changes to the desorption/ionisation model when smaller laser spot sizes are employed. They contrasted this with earlier work that suggested that thermal processes dominated at smaller spot sizes. ${ }^{57}$ There are many fields where improved spatial resolution in images offers opportunities to explore new science. In the field of fingermark analysis, high spatial resolution is particularly important to provide as many minutiae as possible (local characteristics of the fingermark ridge pattern, unique, as a whole, to an individual) helping with the identification of a suspect. The increased lateral resolution to $15 \mu \mathrm{m}$ with the $\mu$ MALDI source enables the provision of comprehensive biometric information, as well as accurately localising forensically relevant compounds. For example, a species that is localising precisely on the pores of the ridges would indicate a substance that has genuinely originated from the owner of the mark and this information is very helpful to formulate activity level proposition at an investigative and judicial debate level.

\section{Quantitation}

Quantitative (Q)-MSI has emerged as a "hot" topic within pharmaceutical development. Simultaneous quantification and localisation of a targeted drug and its active compounds has been demonstrated by MALDI, DESI, LESA and LA-ICP-MS. ${ }^{58-62}$ Establishing MSI for absolute quantitation, however, has presented challenges in obtaining high precision, accuracy and reproducibility. Due to the well-documented issues with ion suppression analyte extraction and matrix effects, the fundamental aspects of MSI need to be considered in order to 
produce fully validated MSI methodology for quantitative analysis. ${ }^{63-65}$

In Q-MSI, a calibration curve is necessary for the analyte of interest (AOI). Choosing a method to include standards into the experiment in order to construct calibration curves is dependent on the nature of the study, i.e. the tissue type or imaging technique. Spotting standard solutions directly onto the target plate has been discarded for most imaging techniques due to the failure to replicate tissue matrix effects. ${ }^{66}$ As an alternative spotting standards onto or under a control tissue or similar matrix, i.e. gelatin, is often used to recreate ion suppression conditions. ${ }^{67,68} \mathrm{~A}$ criticism of this approach, however, is the calibration variability influenced by a tissue's heterogeneous environment. Russo et al. ${ }^{24}$ reported, however, precise use of the spotting technique by applying nanolitre volumes of a standard solely within the epidermis of a 3D skin model to replicate the absorption distribution region of the drug of interest.

Spiked tissue homogenates are commonly used to create matrix matched standards for accurate replication from sample to sample. ${ }^{58,62}$ Preparation of these mimetic tissue models generally requires large volumes, which can be costly and time consuming. Recently, a study developed a method of freezing serial spiked tissue homogenates within a mould to create a calibration "scale bar" against a sample. 69 This method increases the efficiency of the experiment and reduces preparation time. The amount and cost of control tissues for homogenisation is still a drawback, however, and the process is labour intensive when compared to spotting techniques.

To increase the potential of Q-MSI analysis, an internal standard (IS) can be added to normalise differences in ionisation response across a tissue. An IS must be chemically similar to the target analyte and is ideally a deuterated compound. In the literature there are multiple techniques reported for introducing an IS into MSI experiments. For example, applying the IS beneath the tissue has been reported for MALDI analysis as matrix can extract both the AOI and IS from the tissue during crystallisation. Alternatively, in MALDI-MSI the IS can be premixed with the matrix. More frequently, application of IS by spraying or by use of the spotting techniques are used for other imaging modalities due to the efficiency of IS extraction. ${ }^{59,69,70}$ There is disagreement, however, whether this accurately reflects the analyte extraction from the tissue. However, by spraying or spotting an IS it enables the study of whole tissue sections or a ROI.
The use of Q-MSI has not been widely reported for clinical applications, even though the ability to monitor and quantify drug penetration in tissues is a clear medical need. The heterogeneity of patient tissues is an obvious roadblock on conventional Q-MSI methods. Sammour et al. ${ }^{71}$ have recently published a proof-of-concept study on the integration of Q-MSI into a clinical application. A dilution series was generated by spotting calibrants onto porcine tissue adjacent to tumorous and non-tumorous patient tissues treated with imatinib. Additionally, an IS of deuterated imatinib was sprayed across all tissues. The novel aspect was the employment of a non-linear regression curve as a superior calibration method based on imatinib-containing pixels $(S / N \geq 3)$. This was used to create an accurate and precise methodology that was able to handle highly heterogeneous tissues with different amounts of AOI. Whilst the methodology was not fully validated, this study demonstrates a great application of Q-MSI into clinical pharmacological studies and thus is a major step forward for quantitative capabilities.

\section{Other technological enablers Imaging mass cytometry}

Efforts to increase spatial resolution for sub-cellular detail in tissues have seen the development of a novel, highresolution imaging technique, imaging mass cytometry (IMC), otherwise known as CyTOF imaging. The adaptation of high parameter flow cytometry combined with laser ablation and time-of-flight (TOF) MS fundamentals provides capabilities to analyse 50 specific markers simultaneously within a single tissue sample. ${ }^{72,73}$ Before laser ablation, sectioned tissue undergoes immunostaining with metal-labelled antibodies; the signal is then amplified with a metal chelating polymer or nanoparticle. CyTOF is a powerful multiplex imaging platform that can analyse frozen and FFPE tissue samples at a spatial resolution between $1 \mu \mathrm{m}$ and $500 \mathrm{~nm}$, with capabilities for quantitative analysis. ${ }^{74}$ IMC can reveal molecular signatures with intricate detail in tissues applied to a range of studies from animal tissues in pre-clinical drug development, to patient cohorts or archived samples in clinical applications. An informative review on the principles and emerging applications of IMC has been published by Chang et al., ${ }^{75,76}$ which included their own images as a result of collaboration with the Hedley group and the Fluidigm ${ }^{\circledR}$ team in Canada (Figure 5). IMC was first 
commercialised in 2014 by Fluidigm ${ }^{\circledR}$, and validated by the Bodenmiller group, identifying tumour microenvironment heterogeneity in FFPE human breast cancer samples. ${ }^{77}$ Since this report, IMC has been established for single-cellular phenotyping in a range of clinical cancerous and diseased tissues, ${ }^{76-79}$ in addition to identifying biodistributions of cisplatin in healthy and tumorous tissues. $^{80}$

Although IMC is a powerful platform, there are ongoing developments to further improve its capabilities across applications. A limited number of researchers have access to the Hyperion IMC instrumentation due to relatively expensive running costs and approximately $£ 1.2$ million to purchase. Therefore, projects employing IMC have to consider the project costs. Additionally, the acquisition time alone takes $2 \mathrm{~h}$ per $1 \mathrm{~mm}^{2}$, with time to prepare slides for analysis requiring 2 days. Yet, the standard quality of data produced by IMC provides exceptional detail that has significantly improved how researchers analyse tissues, thus expanding possibilities of many biological applications and emerging as a critical tool for research development and clinical outcome.
In addition to IMC, the development of a similar instrumentation, multiplexed ion beam imaging (MIBI)

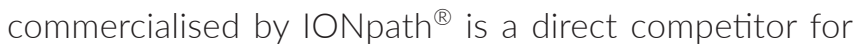
sub-cellular imaging. MIBI coupled with either SIMS or TOF MS enables identification of up to 50 specific biological protein markers at a greater resolution of $200 \mathrm{~nm}$. A number of applications have demonstrated the capabilities of MIBI applied to FFPE and fresh frozen tissues, ${ }^{81,82}$ with possibilities for quantification. ${ }^{83}$ A superior benefit of $\mathrm{MIBI}$ is the application of the ion beam which allows for resampling after acquisition, in contrast to IMC which fully ablates the tissue. However, both techniques still have challenges with validating multiplexed images, for instance visual inspection of antibody specificity by expert pathologists which is crucial but increases the time of data analysis.

\section{LA-ICP-MSI}

An emerging technique in the world of biological MSI is LA-ICP-MSI. Despite being predominantly used previously to visualise the distribution of metallic elements in pathologies associated with metal-dependent

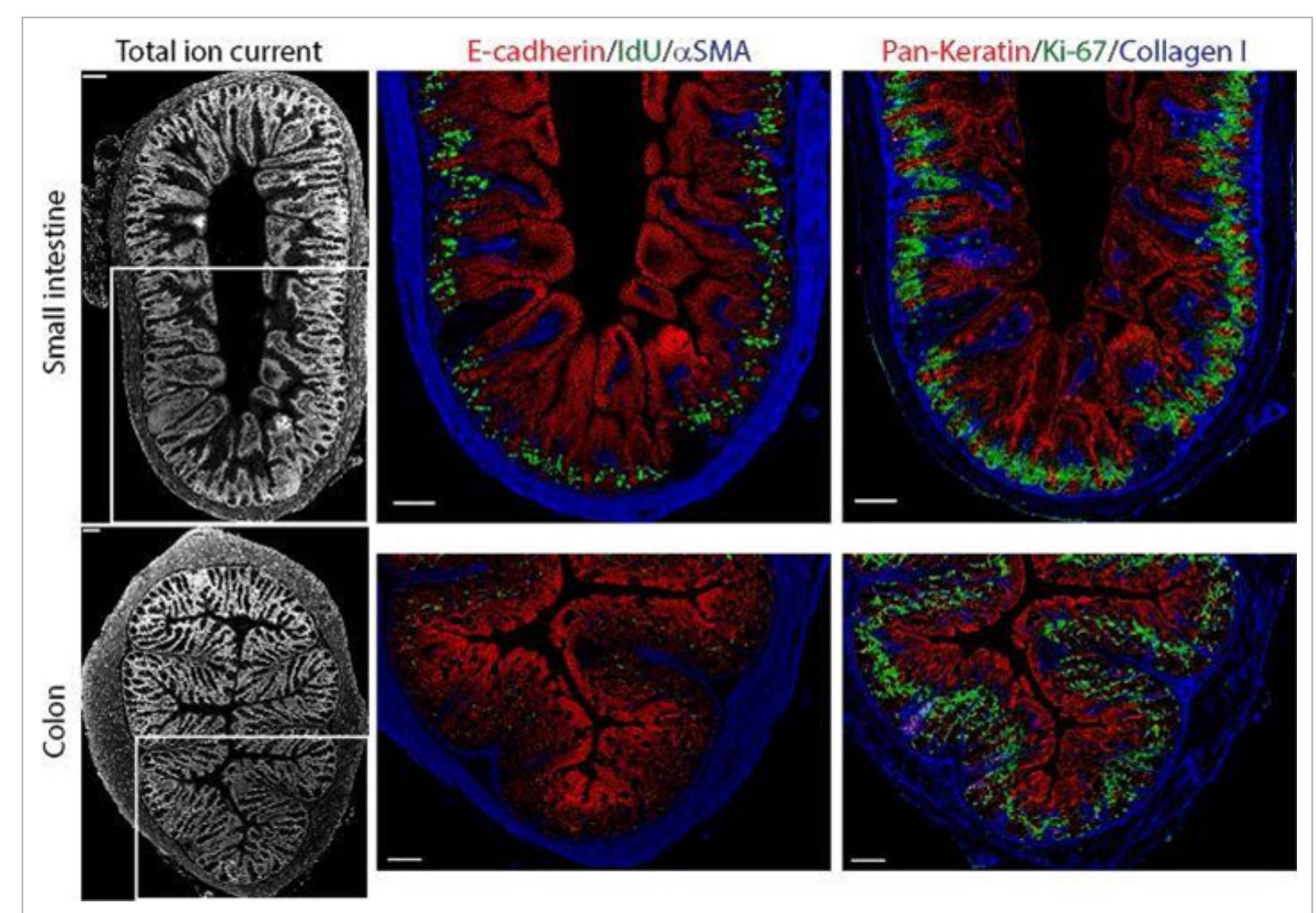

Figure 5. IMC images demonstrating high spatial resolution capabilities by the detection of protein markers in normal mouse small intestine and colon tissues. Image obtained from Reference 75 Chang et al. 2017. 
processes, ${ }^{84}$ LA-ICP-MSI has been gaining momentum in other biomedical applications such as drug monitoring and receptor expression. ${ }^{85}$ One of the limitations of LA-ICP-MSI is the long time between sampling points in which the ablated aerosol is washed out of the ablation cell by the inert gases (e.g. He) to the ICP for ionisation (washout time). This increases analysis times and limits the practicality of the technique for clinical use. One solution would be increasing the sampling rate, but this causes ablated particles to mix and, therefore, decreases sensitivity.

Douglas et al. ${ }^{85}$ have designed a dual volume laser ablation cell with an integrated ICP torch which leads to an increase in absolute sensitivity up to 14 times. A similar design has been employed by Van Acker et al. ${ }^{2}$ to achieve high resolution (sub $\mu \mathrm{m}$ ), single cell imaging of membranous receptors in breast cancer cell lines by attaching a specifically designed diethylenetriaminepentaacetic acid (DTPA) single-lanthanide chelate. The cells were concomitantly stained with a fluorophore which allows multi-imaging of the same sample without further sample preparation or sample denaturation. The group showed the potential of LA-ICP-MSI to offer more information on the microscopic binding pattern of membranous receptors within single breast cancer cells when compared to established techniques such as confocal microscopy. ${ }^{85}$

\section{Trapped ion mobility TOF instruments}

The concept of separating isobaric species in MS has been extensively documented since the first ion mobility QTOF configured instrument became commercially available in $2006 .{ }^{86}$ The notion of trapping ions against a counter flow stream of gas then pushing ions through using the axial voltage of the trap, lead onto the newly developed instrumentation described by FernandezLima et al. ${ }^{87}$ Trapped ion mobility mass spectrometry (TIMS) provides an additional dimension of separation to complement high-performance QTOF technology that results in ion mobility resolution greater than 200. Similar to ion mobility capability, a buffer gas accelerates molecules in proportion to their collisional cross-section. The advantage of TIMS technology is the addition of an electric field that captures these separated ions based on their charge and thus narrow packets of ions can be released by altering the electric field, significantly increasing spectral resolution. If there are still unresolved peaks in the spectra, a narrow $\mathrm{m} / \mathrm{z}$ window can be magnified by adjusting the ion mobility resolution in the TIMS tunnel. This new technology is extremely powerful at resolving overlapping peaks for molecules with identical molecular masses. Spraggins et al. ${ }^{88}$ demonstrated high-resolution imaging capabilities of TIMS coupled to a TOF instrument to separate isobaric phosphatidylcholine species with $3 \mathrm{mDa}$ mass difference in a wholebody mouse pup section at $10 \mu \mathrm{m}$ spatial resolution. The difference between these two species showed distinctive localisations; $\mathrm{PC}(34: 3) \mathrm{H}^{+}$found throughout the tissue, absent within the brain and spinal cord, as PC(32:0) $\mathrm{Na}^{+}$ was significantly localised in the brain, spine and intestines (Figure 6). The ability to separate these isobaric peaks, and thus identifying the differences in localisation, has potential to isolate results that significantly impact a study's outcome.

\section{Improving ionisation efficiency with MALDI-2}

MALDI-2 was originally developed by Niehaus et al.," from the University of Munster to increase sensitivity, mass accuracy and to achieve improvements in spatial resolution. Whilst the increase in spatial resolution is regarded generally as a benefit resulting in more detailed molecular imaging, sub-1 $\mu \mathrm{m}$ pixel size limits sensitivity by reducing the number of available ionised molecules compared to a larger ablation area. Considering that in MSI there is often a small amount of analyte available and that ionisation efficiencies for MALDI are in the region of $1 \times 10^{-4}$ and lower, detecting small quantities can present a problem.

This issue has been addressed with further advancements in MS hardware with the development of the MALDI-2 instrumentation, ${ }^{90,91}$ where an orthogonal postionisation laser triggers a secondary ionisation process of neutral molecules in the gas phase (Figure 7). This is reported to increase ion yields by up to two orders of magnitude. Recent applications include pharmaceutical research ${ }^{91}$ and cell biology, ${ }^{89}$ and report much-improved visualisation of compounds in comparison to conventional MALDI approaches.

\section{Data processing}

Alongside the continuous pressure for technological advancement in MSI is the demand for user friendly, yet dynamic data processing and interpretation tools. The data generated in imaging experiments results in large complex data files (commonly >10 GB per image) 

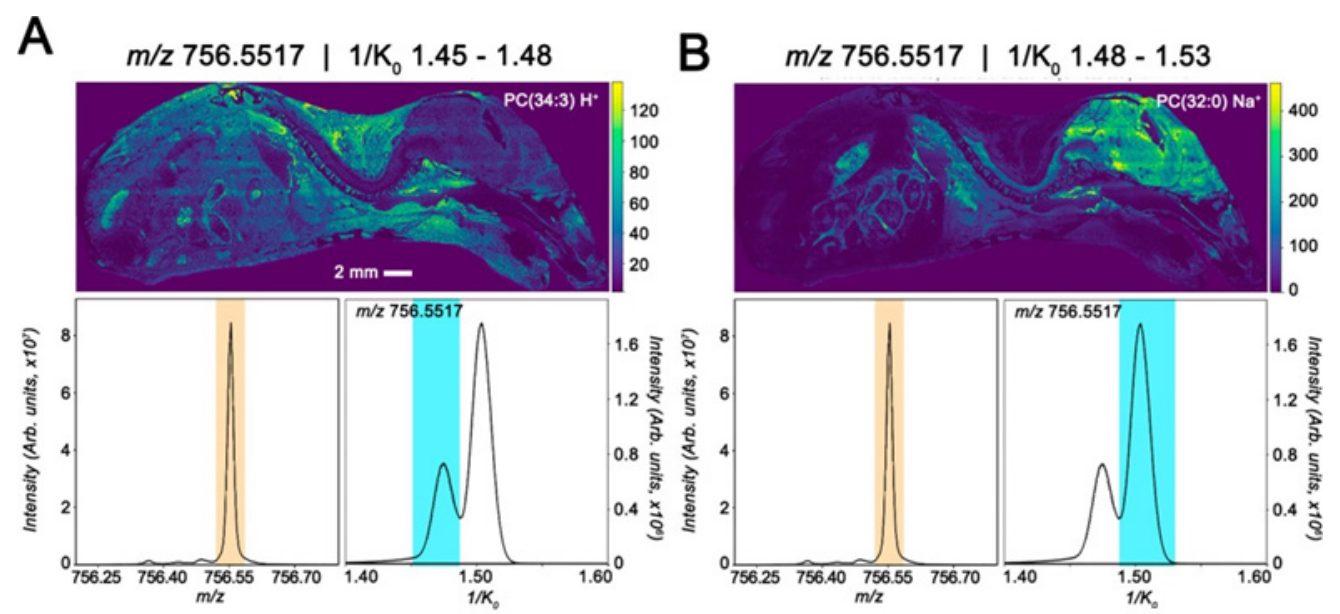

Figure 6. Whole-body mouse pup imaged with timsTOF at $10 \mu \mathrm{m}$. Ion mobility separation of two PC isobaric species localised in two different regions of the mouse pup. A) $\mathrm{PC}(34: 3) \mathrm{H}^{+}$ localised throughout the body. B) PC(32:0) $\mathrm{NA}^{+}$significantly localised within the brain, spinal cord and intestines (adapted from Reference 88.)

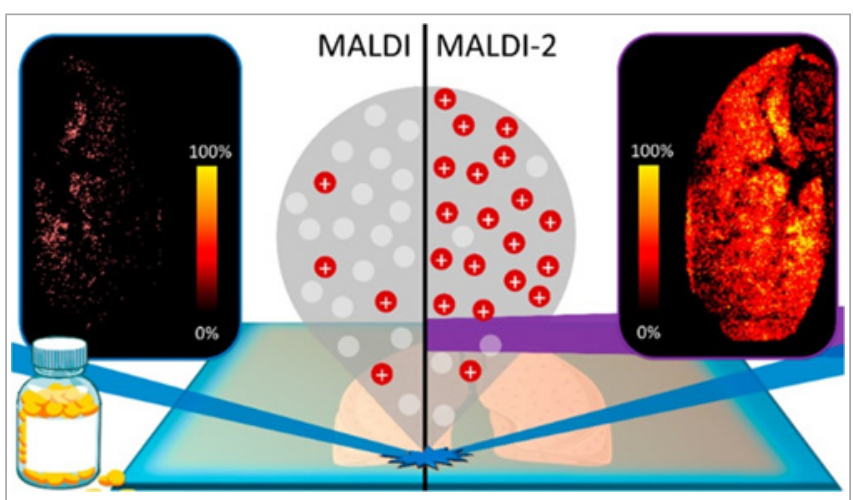

Figure 7. Graphic demonstrating the differences in ionisation between MALDI and MALDI-2 and the corresponding tissue images gained by employing these ionisation methods. (Barre et al. 2019, Reference 91).

which require a multitude of post-image processing steps. Studying a biological molecule of interest within a tissue sample poses a range of potential challenges; post imaging software, therefore, needs to possess a range of toolbox functionalities to correct the issues arising from the sample preparation and image acquisition stages of the experiment described previously. These may include: normalisation, matrix signal removal, baseline correction, noise reduction, spectral alignment and spectral binning.

Each MSI instrument vendor proposes their own proprietary software for the processing of acquired image data. Many of these produce different file types, needing specific and expensive software to open. Although now a familiar concept amongst leading MSI communities, the development of the imzML file format was a pioneering initiative which aimed to address this issue. ${ }^{92}$ The aim of the imzML file format is to facilitate the sharing of imaging data despite the diverse instrumentation and data software currently being used within research groups. Schramm et al. ${ }^{92}$ reported on the potential positive impact that imzML could have on collaborative studies. A standardised file type that could enable comparison of images generated by diverse MSI instrumentation would allow efficient exchange of imaging files between institutions of academia, industries, health services and police forces. This file format for MSI is now employed in many free and commercially available software tools (Table 1).

Multifunctional options offering normalisation, image spectral analysis and advanced integration of multivariate statistics are now common in MSI. However, to enhance, improve and build on image processing strategies there is a need to streamline multidisciplinary modes of data capture along with the ability to be responsive to instrumental inconsistencies. Moreover, processing tools which consider sample batch variation and perform tissue comparisons not only across biological replicates but within the specimens themselves are necessary. Veselkov et al. ${ }^{100}$ described one such innovation and reported a processing platform named pyBASIS (Bioinformatics for MSI in Augmented Systems pathology). This system aims to seamlessly integrate large scale MSI data, molecular network analytics and histological data. pyBASIS features 
Table 1. A summary of software tools currently used and under development in MSI that support the imzML file format (*commercial tools). ${ }^{\text {93-99 }}$

\begin{tabular}{|c|c|}
\hline $\begin{array}{l}\text { Software tools that } \\
\text { implement imzML file format }\end{array}$ & Information brief \\
\hline BioMap & $\begin{array}{l}\text { Requires IDL Virtual Machine to run and no license required. Markus Stoekli: } \\
\text { https://ms-imaging.org/wp/biomap/ }\end{array}$ \\
\hline MSiReader & $\begin{array}{l}\text { Open source vendor-neutral MATLAB (Math Works) application. North } \\
\text { Carolina State University: https://msireader.wordpress.ncsu.edu/ }\end{array}$ \\
\hline Cardinal & $\begin{array}{l}\text { Statistical analysis package. Purdue and Northeastern University: https://cardi- } \\
\text { nalmsi.org/ }\end{array}$ \\
\hline DataCubeExplorer & $\begin{array}{l}\text { Dynamic scrolling, spectral analysis and ROI function. FOM-AMOLF, } \\
\text { Amsterdam: https://amolf.nl/download/datacubeexplorer }\end{array}$ \\
\hline omnispect & $\begin{array}{l}\text { MATLAB-based tool for image visualisation and analysis: https://omictools. } \\
\text { com/omnispect-tool }\end{array}$ \\
\hline SpectralAnalysis & $\begin{array}{l}\text { Analysis software for spectral imaging data. University of Birmingham/NPL: } \\
\text { https://research.birmingham.ac.uk/portal/en/datasets/spectralanalysis-soft- } \\
\text { ware-for-the-masses/ }\end{array}$ \\
\hline CycloBranch & $\begin{array}{l}\text { Software tool for dereplication of organic compounds from MSI datasets: } \\
\text { https://ms.biomed.cas.cz/cyclobranch/docs/html/ }\end{array}$ \\
\hline massPix & $\begin{array}{l}\text { massPix is run using the R scripting interface; high quality images, multivari- } \\
\text { ate statistical analysis. MRC Human Nutrition Research and University of } \\
\text { Cambridge, UK: https://omictools.com/masspix-tool }\end{array}$ \\
\hline msiQuant & $\begin{array}{l}\text { Quantification image visualisation including multiple interpolation methods. } \\
\text { University of Uppsala: https://ms-imaging.org/wp/paquan// }\end{array}$ \\
\hline SpectViewer & $\begin{array}{l}\text { Manipulation of very large imaging data files without the requirement for bin- } \\
\text { ning. Jean-Pierre Both: https://ms-imaging.org/wp/imzml/software-tools/cea- } \\
\text { spect-viewer/ }\end{array}$ \\
\hline MSI.R & $\begin{array}{l}\text { Open source software. CINVESTAV Unidad Irapuato, Mexico: http://lababi. } \\
\text { bioprocess.org/index.php/lababi-software/82-msi-r }\end{array}$ \\
\hline MSIdV & $\begin{array}{l}\text { MSI tool, MSIdV is implemented in Python } 2.7 \text { and is freely available. Kyushu } \\
\text { University: https://sourceforge.net/projects/msidv/ }\end{array}$ \\
\hline LabMSI & $\begin{array}{l}\text { Imaging software for MS. Katsutoshi Takahashi, AIST, Japan: http://www.bio- } \\
\text { image.org/ sltaka/LabMSI/ }\end{array}$ \\
\hline *SCiLS Lab & $\begin{array}{l}\text { Unlimited size processing capacity and statistical analysis. By SCiLS, Bruker. } \\
\text { Capable of 2-D and 3-D modes: https://scils.de/ }\end{array}$ \\
\hline${ }^{*}$ Quantinetix & $\begin{array}{l}\text { Quantinetix imaging software normalises data for quantification. Imabiotech: } \\
\text { https://www.imabiotech.com/quantinetix-mass-spec-imabiotech/ }\end{array}$ \\
\hline *MALDIVision & $\begin{array}{l}\text { Bioinformatics tool for MALDI imaging, 2-D and 3-D modes. PREMIER Biosoft: } \\
\text { http://www.premierbiosoft.com/maldi-tissue-imaging/index.html }\end{array}$ \\
\hline $\begin{array}{l}\text { *High Definition Imaging } \\
\text { (HDI) Software }\end{array}$ & $\begin{array}{l}\text { MSI software, fully integrated for multimodal experimental outputs. Waters: } \\
\text { https://www.waters.com/waters/en_US/High-Definition-Imaging-(HDI)- } \\
\text { Software/nav.htm?cid=134833914\&locale=en_US }\end{array}$ \\
\hline $\begin{array}{l}\text { TizViz } \\
\text { Indigo Platform } \\
\text { MSImage Viewer }\end{array}$ & $\begin{array}{l}\text { Software tools currently under development } \\
\text { TizViz has a beta version available (Christian Fuchsberger), Indigo Platform also } \\
\text { includes DESI image processing (Prosolia, RanyJullian) and MSImage Viewer is } \\
\text { employed in imaging analysis within Novartis (Stoekli lab). }\end{array}$ \\
\hline
\end{tabular}


pattern recognition approaches and employs intuitive "instrumental learning" which focusses on inter-sample (between samples) as opposed to intra-sample (within a sample) normalisation. The differences in normalisation between inter and intra is either a scaling factor applied equally for all spectra within a specific sample or normalisation via the total ion count, respectively, i.e. per spectrum normalisation. The pyBASIS multi-integrated software aims to play a major role in the amalgamation between research and clinically relevant data.

"Masslmager", a software tool produced by He et al., ${ }^{101}$ focuses on in-depth MSI analytics yet employs a user friendly approach at the in situ metabolomics level. This processing platform claims to allow "artificial intelligent pathological diagnosis" and is particularly useful for metabolomic toxicity data. The reasoning behind this is the high-throughput data processing function facilitating observation of pharmacokinetics-absorption, distribution, metabolism and excretion.

Visualisation of endogenous biological molecules can be linked to the presence of other species that co-exist within a tissue specimen. Elemental analysis is one example of how the distribution of biomarkers can be linked to the pathological basis of disease or a specific disease state. "LA-iMageS" is a sophisticated tool developed to study both qualitative and quantitative elemental spatial distribution. ${ }^{102}$ The user is able to visualise an element of interest in a two- or three-dimensional rotational colour map. This open source tool is reported to be easy to operate, omitting the necessity of prior bioinformatics expertise.

The ability to observe both isolated and co-localised signals offers many advantages that would be extremely relevant for pathological and toxicity studies.

\section{Conclusion/future perspective}

The published research within the dynamic field of MS reports innovations in efficient ionisation, mass selection and detection, along with multifunctional data processing analytics. Despite cutting edge techniques there will always be a common ground amongst the MS community, i.e. an expectation from users of continual advancement in all areas that remains constant. Robust reproducible analytical data is vital, without compromising instrumental sensitivity and mass accuracy; an incessant challenge in itself. Whether these remarkable instruments are used individually or as a combined system, here now remains an exciting future for $\mathrm{MSI}$, whatever the area of research may be.

\section{References}

1. R.M. Caprioli, T.B. Farmer and J. Gile, "Molecular imaging of biological samples: localization of peptides and proteins using MALDI-TOF MS", Anal. Chem. 69(23), 4751-4760 (1997). https://doi. org/10.1021/ac970888i

2. T. Van Acker, T. Buckle, S.J.M. Van Malderen, D.M. van Willigen, V. van Unen, F.W.B. van Leeuwen and F. Vanhaecke, "High-resolution imaging and singlecell analysis via laser ablation-inductively coupled plasma-mass spectrometry for the determination of membranous receptor expression levels in breast cancer cell lines using receptor-specific hybrid tracers", Anal. Chim. Acta 1074, 43-53 (2019). https:// doi.org/10.1016/j.aca.2019.04.064

3. H. Li and A.B. Hummon, "Imaging mass spectrometry of three-dimensional cell culture systems", Anal. Chem. 83(22), 8794-8801 (2011). https://doi. org/10.1021/ac202356g

4. A. Dexter, R.T. Steven, A. Patel, L.A. Dailey, A.J. Taylor and D. Ball, "Imaging drugs, metabolites and biomarkers in rodent lung: a DESI MS strategy for the evaluation of drug-induced lipidosis. Analytical and bioanalytical chemistry", Anal. Bioanal. Chem. 411, 8023-8032 (2019). https://doi.org/10.1007/ s00216-019-02151-z

5. P.J. Trim, C.M. Henson, J.L. Avery, A. McEwen, M.F. Snel, E. Claude, P.S. Marshall, A. West, A.P. Princivalle and M.R. Clench, "Matrix-assisted laser desorption/ionization-ion mobility separation-mass spectrometry imaging of vinblastine in whole body tissue sections", Anal Chem. 80(22), 8628-8634 (2008). https://doi.org/10.1021/ac8015467

6. N.E. Mascini, J. Teunissen, R. Noorlag, S.M. Willems and R.M. Heeren, "Tumor classification with MALDI-MSI data of tissue microarrays: A case study", Methods 151, 21-27 (2018). https://doi. org/10.1016/j.ymeth.2018.04.004

7. S. Francese, R. Bradshaw, L.S. Ferguson, R. Wolstenholme, M.R. Clench and S. Bleay, "Beyond the ridge pattern: multi-informative analysis of latent fingermarks by MALDI mass spectrometry", Analyst 
138, 4215-4228 (2013). https://doi.org//10.1039/ C3AN36896C

8. B. Flinders, E. Beasley, R.M. Verlaan, E. Cuypers, S. Francese, T. Bassindale, M.R. Clench and R.M.A. Heeren, "Optimization of sample preparation and instrumental parameters for the rapid analysis of drugs of abuse in hair samples by MALDI-MS/MS imaging", J. Am. Soc. Mass Spectrom. 28(11), 24622468 (2017). https://doi.org/10.1007/s13361-0171766-0

9. S.S. Basu, M.S. Regan, E.C. Randall, W.M. Abdelmoula, A.R. Clark, B. Gimenez-Cassina Lopez, D.S. Cornett, A. Haase, S. Santagata and N.Y.R. Agar, "Rapid MALDI mass spectrometry imaging for surgical pathology", NPJ Precision Oncol. 3, 17 (2019). https://doi.org/10.1038/s41698-019-0089-y

10. P. Saudemont, J. Quanico, Y.-M. Robin, A. Baud, J. Balog, B. Fatou, D. Tierny, Q. Pascal, K. Minier, M. Pottier, C. Focsa, M. Ziskind, Z. Takats, M. Salzet and I. Fournier, "Real-time molecular diagnosis of tumors using water-assisted laser desorption/ionization mass spectrometry technology", Cancer Cell 34(5), P840-851.E4 (2018). https://doi.org/10.1016/j. ccell.2018.09.009

11. R. Ait-Belkacem, V. Bol, G. Hamm, F. Schramme, B. Van Den Eynde, L. Poncelet, F. Pamelard, J. Stauber and B. Gomes, "Microenvironment tumor metabolic interactions highlighted by qMSI: application to the tryptophan-kynurenine pathway in immuno-oncology", SLAS Discov. 22(10), 1182-1192 (2017). https:// doi.org/10.1177/2472555217712659

12. X. Liu, J.K. Lukowski, C. Flinders, S. Kim, R.A. Georgiadis, S.M. Mumenthale and A.B. Hummon, "MALDI-MSI of immunotherapy: mapping the EGFR-targeting antibody cetuximab in 3D colon-cancer cell cultures", Anal. Chem. 90(24), 14156-14164 (2018). https://doi.org/10.1021/acs. analchem.8b02151

13. L. Blanc, A. Lenaerts, V. Dartois and B. Prideaux, "Visualization of mycobacterial biomarkers and tuberculosis drugs in infected tissue by MALDI-MS imaging", Anal. Chem. 90(10), 6275-6282 (2018). https:// doi.org/10.1021/acs.analchem.8b00985

14. H. Bandey, V. Bowman, S. Bleay, R. Downham and V.H. Sears, Fingermark Visualisation Manual. CAST, Home Office, Sandridge, UK (2014).

15. R. Bradshaw, N. Denison and S. Francese, "Implementation of MALDI MS profiling and imaging methods for the analysis of real crime scene fingermarks", Analyst 142, 1581-1590 (2017). https://doi. org/10.1039/C7AN00218A

16. W.E. Grizzle, W.C. Bell and K.C. Sexton, "Issues in collecting, processing and storing human tissues and associated information to support biomedical research", Cancer Biomark. 9(1-6), 531-549 (2011). https://doi.org/10.1007/s00428-015-1825-5

17. L.E. Mignini and K.S. Khan, "Methodological quality of systematic reviews of animal studies: a survey of reviews of basic research", BMC Med. Res. Methodol. 6, 10 (2006). https://doi.org/10.1186/1471-2288-610

18. C. Russo, E.E.L. Lewis, L. Flint and M.R. Clench, "Mass spectrometry imaging of 3D tissue models", Proteomics 18(14), 1700462 (2018). https://doi. org/10.1002/pmic.201700462

19. J.K. Lukowski, E.M. Weaver and A.B. Hummon, "Analyzing liposomal drug delivery systems in three-dimensional cell culture models using MALDI imaging mass spectrometry", Anal. Chem. 89(16), 8453-8458 (2017). https://doi.org/10.1021/acs. analchem.7b02006

20. P.E. Feist, S. Sidoli, X. Liu, M.M. Schroll, S. Rahmy, R. Fujiwara, G.A. Benjamin and A.B. Hummon, "Multicellular tumor spheroids combined with mass spectrometric histone analysis to evaluate epigenetic drugs", Anal. Chem. 89(5), 2773-2781 (2017). https:// doi.org/10.1021/acs.analchem.6b03602

21. X. Liu X. E.M. Weaver and A.B. Hummon, "Evaluation of therapeutics in three-dimensional cell culture systems by MALDI imaging mass spectrometry", Anal. Chem. 85(13), 6295-6302 (2013). https:// doi.org/10.1021/ac400519c

22. E. Bellas, M. Seiberg, J. Garlick and D.L. Kaplan, "In vitro 3D full thickness skin equivalent tissue model using silk and collagen biomaterials", Macromol. Biosci. 12(12), 1627-1636 (2012). https://doi.org/10.1002/ mabi.201200262

23. A. Harvey, L.M. Cole, R. Day, J. Warwick, R. Bojar, D. Smith, N. Cross and M.R. Clench, "MALDI-MSI for the analysis of 3D tissue-engineered psoriatic skin model", Proteomics 16(11-12), 1718-1725 (2016). https://doi.org/10.1002/pmic.201600036

24. C. Russo, N. Brickelbank, C. Duckett, S. Mellor, S. Rumbelow and M.R. Clench, "Quantitative investigation of terbinafine hydrochloride absorption into a living skin equivalent model by MALDI-MSI", Anal. 
Chem. 90(16), 10031-10038 (2018). https://doi. org/10.1021/acs.analchem.8b02648

25. E.E.L. Lewis, M.R.T. Barrett, L. Freeman-Parry, R.A. Bojar and M.R. Clench, "Examination of the skin barrier repair/wound healing process using a living skin equivalent model and matrix-assisted laser desorption-ionization-mass spectrometry imaging", Int. J. Cosmet. Sci. 40(2), 148-156 (2018). https://doi. org/10.1111/ics.12446

26. S. Francese, R. Bradshaw and N. Denison, "An update on MALDI mass spectrometry based technology for the analysis of fingermarks - stepping into operational deployment", Analyst 142, 2518-2546 (2017). https://doi.org//10.1039/C7AN00569E

27. R. Bradshaw, R. Wolstenholme and L.S. Ferguson, "Spectroscopic imaging based approach for condom identification in condom contaminated fingermarks", Analyst 138, 2546-2557 (2013). https://doi. org/10.1039/c3an00195d

28. H. Reed, A. Stanton, J. Wheat, J. Kelley, L. Davis, W. Rao, A. Smith, D. Owen and S. Francese, "The ReedStanton press rig for the generation of reproducible fingermarks: towards a standardised methodology for fingermark research", Sci. Justice 56(1), 9-17 (2016). https://doi.org/10.1016/j.scijus.2015.10.001

29. E.L. Gill, R.A. Yost, V. Vedam-Mai and T.J. Garrett, "Precast gelatin-based molds for tissue embedding compatible with mass spectrometry imaging", Anal. Chem. 89(1), 576-580 (2017). https://doi. org/10.1021/acs.analchem.6b04185

30. K.A. Nelson, G.J. Daniels, J.W. Fournie and M.J. Hemmer, "Optimization of whole-body zebrafish sectioning methods for mass spectrometry imaging", J. Biomol. Tech. 24(3), 119-127 (2013). https://doi. org/10.7171/jbt.13-2403-002

31. M. Strohalm, J. Strohalm, F. Kaftan, L. Krásný, M. Volný, P. Novák, K. Ulbrich and V. Havlíček, "Poly[N(2-hydroxypropyl)methacrylamide]-based tissueembedding medium compatible with MALDI mass spectrometry imaging experiments", Anal. Chem. 83(13), 5458-5462 (2011). https://doi.org/10.1021/ ac2011679

32. A. Ly, A. Buck., B. Balluff, N. Sun, K. Gorzolka, A. Feuchtinger, K.P. Janssen, P.J.K. Kuppen, C.J.H. van de Velde, G. Weirich, F. Erlmeier, R. Langer, M. Aubele, H. Zitzelsberger, L. McDonnell, M. Aichler and A. Walch, "High-mass-resolution MALDI mass spectrometry imaging of metabolites from formalin-fixed paraffin-embedded tissue", Nat. Protoc. 11, 1428-1443 (2016). https://doi. org/10.1038/nprot.2016.081

33. A. Dannhorn, E. Kazanc, S. Ling, C. Nikula, E. Karali, M.P. Serra, J.-L. Vorng, P. Inglese, G. Maglennon, G. Hamm, J. Swales, N. Strittmatter, S.T. Barry, O.J. Sansom, G. Poulogiannis, J. Bunch, R.J.A. Goodwin and Z. Takats, "Universal sample preparation unlocking multimodal molecular tissue imaging", Anal. Chem. 92(16), 11080-11088 (2020). https://doi. org/10.1021/acs.analchem.0c00826

34. A. Ly, R. Longuespée, R. Casadonte, P. Wandernoth, K. Schwamborn, C. Bollwein, C. Marsching, K. Kriegsmann, C. Hopf, W. Weichert, J. Kriegsmann, P. Schirmacher, M. Kriegsmann and S.-O. Deininger, "Site-to-site reproducibility and spatial resolution in MALDI-MSI of peptides from formalin-fixed paraffin-embedded samples", Proteom. Clin. Appl. 13(1), 1800167 (2019). https://doi.org/10.1002/ prca.201800029

35. R. Longuespée, K. Kriegsmann, M. Cremer, C. Zgorzelski, R. Casadonte, D. Kazdal, J. Kriegsmann, W. Weichert, K. Schwamborn, M. Fresnais, P. Schirmacher and M. Kriegsmann, "In MALDI-mass spectrometry imaging on formalin-fixed paraffinembedded tissue specimen section thickness significantly influences $\mathrm{m} / \mathrm{z}$ peak intensity", Proteom. Clin. Appl. 13(1), 1800074 (2019). https://doi. org/10.1002/prca.201800074

36. P.M. Angel, S. Comte-Walters, L.E. Ball, K. Talbot, A. Mehta, K.G.M. Brockbank and R.R. Drake, "Mapping extracellular matrix proteins in formalin-fixed, paraffin-embedded tissues by MALDI imaging mass spectrometry", J. Proteome Res. 17(1), 635-646 (2018). https://doi.org/10.1021/acs.jproteome.7b00713

37. E. Berghmans, G. Van Raemdonck, K. Schildermans, H. Willems, K. Boonen, E. Maes, I. Mertens, P. Pauwels and G. Baggerman, "MALDI mass spectrometry imaging linked with top-down proteomics as a tool to study the non-small-cell lung cancer tumor microenvironment", Method. Protoc. 2(2), 44 (2019). https://doi.org/10.3390/mps2020044

38. P. Sjövall, B. Johansson and J. Lausmaa, "Localization of lipids in freeze-dried mouse brain sections by imaging TOF-SIMS", Appl. Surf. Sci. 252(19), 6966-6974 (2006). https://doi.org/10.1016/j. apsusc.2006.02.126 
39. T. Porta Siegel, G. Hamm, J. Bunch, J. Cappell, J.S. Fletcher and K. Schwamborn, "Mass spectrometry imaging and integration with other imaging modalities for greater molecular understanding of biological tissues", Mol. Imaging Biol. 20, 888-901 (2018). https://doi.org/10.1007/s11307-018-1267-y

40. J.G. Swales, A. Dexter, G. Hamm, A. Nilsson, N. Strittmatter, F. Michopoulos, C. Hardy, P. MorentinGutierrez, M. Mellor, P.E. Andren, M.R. Clench, J. Bunch, S.E. Critchlow and R.J.A. Goodwin, "Quantitation of endogenous metabolites in mouse tumors using mass-spectrometry imaging", Anal. Chem. 90(10), 6051-6058 (2018). https://doi. org/10.1021/acs.analchem.7b05239

41. L.M. Cole, M.-C. Djidja, J. Bluffb, E. Claude, V.A. Carolan, M. Paley, G.M. Tozer and M.R. Clench, "Investigation of protein induction in tumour vascular targeted strategies by MALDI MSI", Methods 54(4), 442-453 (2011). https://doi.org/10.1016/j. ymeth.2011.03.007

42. A. Ly, R. Longuespée, R. Casadonte, P. Wandernoth, K. Schwamborn, C. Bollwein, C. Marsching, K. Kriegsmann, C. Hopf, W. Weichert, K. Wilko, J. Kriegsmann, P. Schirmacher, M. Kriegsmann and S.O. Deininger, "Site-to-site reproducibility and spatial resolution in MALDI-MSI of peptides from formalin-fixed paraffin embedded samples", Proteom. Clin. Appl. 13(1), 1800029 (2019). https://doi. org/10.1002/prca.201800029

43. A.S. Attia, K.A. Schroeder, E.H. Seeley, K.J. Wilson, N.D. Hammer, D.C. Colvin, M.L. Manier, J.J. Nicklay, K.L. Rose, J.C. Gore, R.M. Caprioli and E.P. Skaa, "Monitoring the Inflammatory response to infection through the integration of MALDI IMS and MRI", Cell Host Microbe 11(6), 664-673 (2012). https://doi. org/10.1016/j.chom.2012.04.018

44. M. Schuerenberg, C. Luebbert, S. Deininger, R. Ketterlinus and D. Suckau, "MALDI tissue imaging: mass spectrometric localization of biomarkers in tissue slices", Nat. Methods 4, 462 (2007). https://doi. org/10.1038/nmeth1039

45. E.R. St John, J. Balog, J.S. McKenzie, M. Rossi, A. Covington, L. Muirhead, Z. Bodai, F. Rosini, A.V.M. Speller, S. Shousha, R. Ramakrishnan, A. Darzi and Z. Takats, "Rapid evaporative ionisation mass spectrometry of electrosurgical vapours for the identification of breast pathology: towards an intelligent knife for breast cancer surgery", Breast Cancer Res.
19, 59 (2017). https://doi.org/10.1186/s13058-0170845-2

46. J. Zhang, J. Rector, J.Q. Lin, J.H. Young, M. Sans, N. Katta, N. Giese, W. Yu, C. Nagi, J. Suliburk, J. Liu, A. Bensussan, R.J. DeHoog, K.Y. Garza, B. Ludolph, A.G. Sorace, A. Syed, A. Zahedivash, T.E. Milner and L.S. Eberlin, "Nondestructive tissue analysis for ex vivo and in vivo cancer diagnosis using a handheld mass spectrometry system", Sci. Transl. Med. 9(406), eaan3968 (2017). https://doi.org/10.1126/scitransImed.aan3968

47. F. Pragst and M.A. Balikova, "State of the art in hair analysis for detection of drug and alcohol abuse", Clin. Chim. Acta 370(1-2), 17-49 (2006). https://doi. org/10.1016/j.cca.2006.02.019

48. E. Lendoiro, C. Jiménez-Morigosa, A. Cruz, M. Páramo, M. López-Rivadulla and A. Castro, "An LC-MS/MS methodological approach to the analysis of hair for amphetamine-type-stimulant (ATS) drugs, including selected synthetic cathinones and piperazines", Drug Test. Anal. 9(1), 96-105 (2017). https:// doi.org/10.1002/dta.1948

49. A. Orfanidis, O. Mastrogianni, A. Koukou, G. Psarros, H. Gika, G. Theodoridis and N. Raikos, "A GC-MS method for the detection and quantitation of ten major drugs of abuse in human hair samples", J. Chromatogr. B 1047, 141-150 (2017). https://doi. org/10.1016/j.jchromb.2016.11.011

50. E. Beasley, S. Francese and T. Bassindale, "Detection and mapping of cannabinoids in single hair samples through rapid derivatization and matrix-assisted laser desorption ionization mass spectrometry", Anal. Chem. 88(20), 10328-10334 (2016). https://doi. org/10.1021/acs.analchem.6b03551

51. B. Flinders, E. Cuypers, H. Zeijlemaker J. Tytgat and R.M.A. Heeren, "Preparation of longitudinal sections of hair samples for the analysis of cocaine by MALDI-MS/MS and TOF-SIMS imaging", Drug Test. Anal. 7(10), 859-865 (2015). https://doi. org/10.1002/dta.1812

52. R. Ait-Belkacem, C. Berenguer, C. Villard, L. Ouafik, D. Figarella-Branger, A. Beck, O. Chinot and D. Lafitte, "Monitoring therapeutic monoclonal antibodies in brain tumor", mAbs 6(6), 1385-1393 (2014). https://doi.org/10.4161/mabs.34405

53. D. Debois, V. Bertrand, L. Quinton, M. De PauwGillet and E. De Pauw, "MALDI-in source decay applied to mass spectrometry imaging: a new tool 
for protein identification", Anal. Chem. 82(10), 40364045 (2010). https://doi.org/10.1021/ac902875q

54. X. Liu, C. Flinders, S.M. Mumenthaler and A.B. Hummon, "MALDI mass spectrometry imaging for evaluation of therapeutics in colorectal tumor organoids", J. Am. Soc. Mass Spectrom. 29(3), 516-526 (2018). https://doi.org/10.1007/s13361-017-1851-4

55. F. Barré, B. Rocha, F. Dewez, M. Towers, P. Murray, E. Claude, B.C. Pastora, R. Heeren and T. Porta Siegel, "Faster raster matrix-assisted laser desorption/ionization mass spectrometry imaging of lipids at high lateral resolution", Int. J. Mass Spectrom. 437, 38-48 (2019). https://doi.org/10.1016/j. ijms.2018.09.015

56. S. Guenther, M. Koestler, O. Schulz and B. Spengler, "Laser spot size and laser power dependence of ion formation in high resolution MALDI imaging", Int. J. Mass Spectrom. 294(1), 7-15 (2010). https://doi. org/10.1016/j.ijms.2010.03.014

57. K. Dreisewerd, M. Schürenberg, M. Karas and F. Hillenkamp, "Influence of the laser intensity and spot size on the desorption of molecules and ions in matrix-assisted laser desorption/ ionization with a uniform beam profile", Int. J. Mass Spectrom. 141(2), 127-148 (1995). https://doi. org/10.1016/0168-1176(94)04108-J

58. A.R. Roddy and J.D. Stosz, "Fingerprint featuresstatistical analysis and system performance estimates", Proc. IEEE 85(9), 1390-1421 (1997). https:// doi.org/10.1109/5.628710

59. M.R. Groseclose and S. Castellino, "A mimetic tissue model for the quantification of drug distributions by MALDI imaging mass spectrometry", Anal. Chem. 85(21), 10099-10106 (2013). https://doi. org/10.1021/ac400892z

60. H.T. Hansen and C. Janfelt, "Aspects of quantitation in mass spectrometry imaging investigated on cryo-sections of spiked tissue homogenates", Anal. Chem. 88(23), 11513-11520 (2016). https://doi. org/10.1021/acs.analchem.6b02711

61. J.G. Swales, N. Strittmatter, J.W. Tucker, M.R. Clench, P.J.H. Webborn and R.J.A. Goodwin, "Spatial quantitation of drugs in tissues using liquid extraction surface analysis mass spectrometry imaging", Sci. Rep. 6, 37648 (2016). https://doi.org/10.1038/srep37648

62. D.J. Hare, J. Lear, D. Bishop, A. Beavis and P.A. Doble, "Protocol for production of matrixmatched brain tissue standards for imaging by laser ablation-inductively coupled plasma-mass spectrometry", Anal. Methods 5, 1915-1921 (2013). https:// doi.org/10.1039/C3AY26248K

63. F. Tobias and A.B. Hummon, "Considerations for MALDI-based quantitative mass spectrometry imaging studies", J. Proteome Res. 9, 3620-3630 (2020). https://doi.org/10.1021/acs.jproteome.0c00443

64. S.R. Ellis, A.L. Bruinen and R.M.A. Heeren, "A critical evaluation of the current state-of-the-art in quantitative imaging mass spectrometry", Anal. Bioanal. Chem. 406, 1275-1289 (2014). https://doi. org/10.1007/s00216-013-7478-9

65. I. Rzagalinski and D.A. Volmer, "Quantification of low molecular weight compounds by MALDI imaging mass spectrometry - A tutorial review", Biochim. Biophys. Acta Proteins Proteom. 1865(7), 726-739 (2017). https://doi.org/10.1016/j.bbapap.2016.12.011

66. J. Barry, J.A. Barry, M.R. Groseclose, D.D. Fraser and S. Castellino, "Revised preparation of a mimetic tissue model for quantitative imaging mass spectrometry", Protoc. Exchange (2018). https://doi. org/10.1038/protex.2018.104

67. M. Lagarrigue, R. Lavigne, E. Tabet, V. Genet, J. Thomé, K. Rondel, B. Guével, L. Multigner, M. Samson and C. Pineau, "Localization and in situ absolute quantification of chlordecone in the mouse liver by MALDI imaging", Anal. Chem. 86(12), 57755783 (2014). https://doi.org/10.1021/ac500313s

68. D.A. Pirman, R.F. Reich, A. Kiss, R.M.A. Heeren and R.A. Yost, "Quantitative MALDI tandem mass spectrometric imaging of cocaine from brain tissue with a deuterated internal standard", Anal. Chem. 85(2), 1081-1089 (2013). https://doi.org/10.1021/ ac302960j

69. J.A. Barry, M.R. Groseclose and S. Castellino, "Quantification and assessment of detection capability in imaging mass spectrometry using a revised mimetic tissue model", Bioanalysis 11(11), 1099-1116 (2019). https://doi.org/10.4155/bio-2019-0035

70. Q. Wu, Z. Huang, Y. Wang, Z. Zhang and H. Lu, "Absolute quantitative imaging of sphingolipids in brain tissue by exhaustive liquid microjunction surface sampling-liquid chromatography-mass spectrometry", J. Chromatogr. A 1609, 460436 (2019). https://doi.org/10.1016/j.chroma.2019.460436

71. D.A. Sammour, C. Marsching, A. Geisel, K. Erich, S. Schulz, C. Ramallo Guevara, J.-H. Rabe, 
A. Marx, P. Findeisen, P. Hohenberger and C. Hopf, "Quantitative mass spectrometry imaging reveals mutation status-independent lack of imatinib in liver metastases of gastrointestinal stromal tumors", Sci. Rep. 9, 10698 (2019). https://doi.org/10.1038/ s41598-019-47089-5

72. C. Giesen, H.A.O. Wang, D. Schapiro, N. Zivanovic, A. Jacobs, B. Hattendorf, P.J. Schüffler, D. Grolimund, J.M. Buhmann, S. Brandt, Z. Varga, P.J. Wild, D. Günther and B. Bodenmiller, "Highly multiplexed imaging of tumor tissues with subcellular resolution by mass cytometry", Nat. Methods 11, 417-422 (2014). https://doi.org/10.1038/nmeth.2869

73. S.C. Bendall, E.F. Simonds, P. Qiu, E.D. Amir, P.O. Krutzik, R. Finck, R.V. Bruggner, R. Melamed, A. Trejo, O.I. Ornatsky, R.S. Balderas, S.K. Plevritis, K. Sachs, D. Pe'er, S.D. Tanner and G.P. Nolan, "Singlecell mass cytometry of differential immune and drug responses across a human hematopoietic continuum", Science 332(6030), 687-696 (2011). https:// doi.org/10.1126/science.1198704

74. E.R. Parra, A. Francisco-Cruz and I.I. Wistuba, "State-of-the-art of profiling immune contexture in the era of multiplexed staining and digital analysis to study paraffin tumor tissues", Cancers 11(2), 247 (2019). https://doi.org/10.3390/cancers11020247

75. Q. Chang, O.I. Ornatsky, I. Siddiqui, A. Loboda, V.I. Baranov and D.W. Hedley, "Imaging mass cytometry", Cytom. Part A 91(2), 160-169 (2017). https:// doi.org/10.1002/cyto.a.23053

76. D. Schulz, V.R.T. Zanotelli, J.R. Fischer, D. Schapiro, S. Engler, X. Lun, H.W. Jackson and B. Bodenmiller, "Simultaneous multiplexed imaging of mRNA and proteins with subcellular resolution in breast cancer tissue samples by mass cytometry", Cell Syst. 6(1), P25-36.E5 (2018). https://doi.org/10.1016/j. cels.2017.12.001

77. N. Damond, S. Engler, V.R.T. Zanotelli, D. Schapiro, C.H. Wasserfall, I. Kusmartseva, H.S. Nick, F. Thorel, P.L. Herrera, M.A. Atkinson and B. Bodenmiller, "Imaging mass cytometry analysis of the natural history of Type 1 diabetes", Cell Metab. 29(3), P755-768.E5 (2019). https://doi.org/10.1016/j. cmet.2018.11.014

78. M.E. ljsselsteijn, R. van der Breggen, A. Farina Sarasqueta, F. Koning and N.F.C.C. de Miranda, "A 40-marker panel for high dimensional characterization of cancer immune microenvironments by imaging mass cytometry", Front. Immunol. 10, 2534 (2019). https://doi.org/10.3389/fimmu.2019.02534

79. A. Bouzekri, A. Esch and O. Ornatsky,

"Multidimensional profiling of drug-treated cells by imaging mass cytometry", FEBS Open Bio 9(9), 1652-1669 (2019). https://doi.org/10.1002/22115463.12692

80. Q. Chang, O.I. Ornatsky, I. Siddiqui, R. Straus, V.I. Baranov and D.W. Hedley, "Biodistribution of cisplatin revealed by imaging mass cytometry identifies extensive collagen binding in tumor and normal tissues", Sci. Rep. 6, 36641 (2016). https://doi. org/10.1038/srep36641

81. M. Angelo, S.C. Bendall, R. Finck, M.B. Hale, C. Hitzman, A.D. Borowsky, R.M. Levenson, J.B. Lowe, S.D. Liu, S. Zhao, Y. Natkunam and G.P. Nolan, "Multiplexed ion beam imaging of human breast tumors", Nat. Med. 20, 436-442 (2014). https://doi. org/10.1038/nm.3488

82. L. Keren, M. Bosse, T.S. Risom, K. Vijayaragavan, E. McCaffrey, D. Marquez, R. Angoshtari, N.F. Greenwald, H. Fienberg, J. Wang, N. Kambham, D. Kirkwood, G. Nolan, T.J. Montine, S.J. Galli, R. West, S.C. Bendall and M. Angelo, "MIBI-TOF: A multiplexed imaging platform relates cellular phenotypes and tissue structure", Sci. Adv. 5(10), eaax5851 (2019). https://doi.org/10.1126/sciadv.aax5851

83. S. Rost, J. Giltnane, J.M. Bordeaux, C. Hitzman, $H$. Koeppen and S.D. Liu, "Mulitplexed ion beam imaging analysis for quantification of protein expression in cancer tissue sections", Lab. Invest. 97, 992-1003 (2017). https://doi.org/10.1038/labinvest.2017.50

84. J.S. Becker, A. Matusch, C. Palm, D. Salber, K.A. Morton and J.S. Becker, "Bioimaging of metals by laser ablation inductively coupled plasma mass spectrometry (LA-ICP-MS)", Metallomics 2, 104-111 (2010). https://doi.org/10.1039/B916722F

85. D.N. Douglas, A.J. Managh, H.J. Reid and B.L. Sharp, "High-speed, integrated ablation cell and dual concentric injector plasma torch for laser ablationinductively coupled plasma mass spectrometry", Anal. Chem. 87(22), 11285-11294 (2015). https://doi. org/10.1021/acs.analchem.5b02466

86. A. Loboda, "Novel ion mobility setup combined with collision cell and time-of-flight mass spectrometer", J. Am. Soc. Mass Spectrom. 17(5), 691-699 (2006). https://doi.org/10.1016/j.jasms.2006.01.013 
87. F. Fernandez-Lima, D.A. Kaplan, J. Suetering and M.A. Park, "Gas-phase separation using a trapped ion mobility spectrometer", Int. J. Ion. Mobil. Spectrom. 14, 93-98 (2011). https://doi.org/10.1007/ S12127-011-0067-8

88. J. Spraggins, K. Djambazova, E. Rivera, L. Migas, E. Neumann, A. Fuetterer, J. Suetering, N. Goedecke, A. Ly, R. Van de Plas and R.M. Caprioli, "High performance molecular imaging with MALDI trapped ion mobility time-of-flight (timsTOF) mass spectrometry", Anal. Chem. 91(22), 14552-14560 (2019). https://doi.org/10.1021/acs.analchem.9b03612

89. M. Niehaus, J. Soltwisch, M.E. Belov and K. Dreiswerd, "Transmission-mode MALDI-2 mass spectrometry imaging of cells and tissues at subcellular resolution", Nat. Methods 16, 925-931 (2019). https://doi.org/10.1038/s41592-019-0536-2

90. J. Soltwisch, H. Kettling, S. Vens-Cappell, M. Wiegelmann, J. Müthing and K. Dreisewerd, "Mass spectrometry imaging with laser-induced postionization", Science 348(6231), 211-215 (2015). https://doi. org/10.1126/science.aaa1051

91. F.P.Y. Barre, M.R.L. Paine, B. Flinders, A.J. Trevitt, P.D. Kelly, R. Ait-Belkacem, J.P. Garcia, L.B. Creemers, J. Stauber, R.J. Vreeken, B. Cillero-Pastor, S.R. Ellis and R.M.A. Heeren, "Enhanced sensitivity using MALDI imaging coupled with laser postionization (MALDI-2) for pharmaceutical research", Anal. Chem. 91(16), 10840-10848 (2019). https://doi. org/10.1021/acs.analchem.9b02495

92. T. Schramm, A. Hester, I. Klinkert, J. Both, R.M.A. Heeren, A. Brunelle, O. Laprévote, N. Desbenoit, M.-F. Robbe, M. Stoeckli, B. Spengler and A. Römpp, "imzML - A common data format for the flexible exchange and processing of mass spectrometry imaging data", J. Proteomics 75(16), 5106-5110 (2012). https://doi.org/10.1016/j.jprot.2012.07.026

93. K.D. Bemis, A. Harry, L.S. Eberlin, C. Ferreira, S.M. van de Ven, P. Mallick, M. Stolowitz and O. Vitek, "Cardinal: An R package for statistical analysis of mass spectrometry-based imaging experiments", Bioinformatics 31(14), 2418-2420 (2015). https://doi. org/10.1093/bioinformatics/btv146

94. A.M. Race, A.D. Palmer, A. Dexter, R.T. Steven, I.B. Styles and J. Bunch, "SpectralAnalysis: software for the masses", Anal. Chem. 88(19), 9451-9458 (2016). https://doi.org/10.1021/acs.analchem.6b01643
95. J. Novák, K. Lemr, K.A. Schug and V. Havlíček, "CycloBranch: de novo sequencing of nonribosomal peptides from accurate product ion mass spectra", J. Am. Soc. Mass Spectrom. 26(10), 1780-1786 (2015). https://doi.org/10.1007/s13361-015-1211-1

96. C. Henkel and P. Hoffmann, "MALDI imaging; proteins and proteomics", Biochim. Biophys. Acta 1865(7), 725-978 (2017). https://doi.org/10.1016/j. bbapap.2017.05.008

97. P. Källback, A. Nilsson, M. Shariatgorji and P.E. Andrén, "mslQuant - quantitation software for mass spectrometry imaging enabling fast access, visualization, and analysis of large data sets", Anal. Chem. 88(8), 4346-4353 (2016). https://doi.org/10.1021/ acs.analchem.5b04603

98. E. Hayakawa, Y. Fujimura and D. Miura, "MSIdV: a versatile tool to visualize biological indices from mass spectrometry imaging data", Bioinformatics 32(24), 3852-3854 (2016). https://doi.org/10.1093/ bioinformatics/btw548

99. MS Imaging; Home of Mass Spectrometry Imaging. https://ms-imaging.org/wp/ (Accessed 17 July 2018). 100. K. Veselkov, J. Sleeman, E. Claude, J.P.C. Vissers, D. Galea, A. Mroz, I. Laponogov, M. Towers, R. Tonge, R. Mirnezami, Z. Takats, J.K. Nicholson and J.I. Langridge, "BASIS: High-performance bioinformatics platform for processing of large-scale mass spectrometry imaging data in chemically augmented histology", Sci. Rep. 8, 4053 (2018). https://doi. org/10.1038/s41598-018-22499-z

101. J. He, L. Huang, R. Tian, X. Li, T. Li, C. Sun, X. Song, Y. Lv, Z. Luo, X. Li and Z. Abliz, "Masslmager: A software for interactive and in-depth analysis of mass spectrometry imaging data", Anal. Chim. Acta 1015, 50-57 (2018). https://doi.org/10.1016/j. aca.2018.02.030

102. H. López-Fernández, G. de S. Pessôa, M.A.Z. Arruda, J.L. Capelo-Martínez, F. Fdez-Riverola, D. Glez-Peña and M. Reboiro-Jato, "LA-iMageS: a software for elemental distribution bioimaging using LAICP-MS data", J. Cheminform. 8, 65 (2016). https:// doi.org/10.1186/s13321-016-0178-7 